NATIONAL LABORATORY

MANAGED BY UT-BATTELLE

FOR THE DEPARTMENT OF ENERGY

\title{
Waste Preparation and Transport Chemistry: Results of the FY 2000 Studies
}

\author{
R. D. Hunt \\ T. A. Dillow \\ J. R. Parrott, Jr. \\ J. C. Schryver \\ C. F. Weber \\ T. D. Welch
}

Tanks

Focus

Area ,

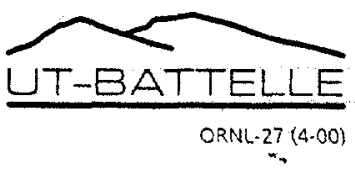



Chemical Technology Division

Waste Preparation and Transport Chemistry: Results of the FY 2000 Studies
R. D. Hunt
J. C. Schryver*
T. A. Dillow
C. F. Weber ${ }^{\dagger}$
J. R. Parrott, Jr.
T. D. Welch

*Computer Science and Mathematics Division, ORNL

${ }^{\dagger}$ Computational Physics and Engineering Division, ORNL

December 2000

Prepared for the Tanks Focus Area

DOE Office of Science and Technology

in fulfillment of

Milestones A.1.1-2 and A.2.1-3 of

TTP OR16WT41

Prepared by the

OAK RIDGE NATIONAL LABORATORY

Oak Ridge, Tennessee 37831-6285

managed by

UT-BATTELLE, LLC

for the

U.S. DEPARTMENT OF ENERGY

under contract DE-AC05-00OR22725 


\section{CONTENTS}

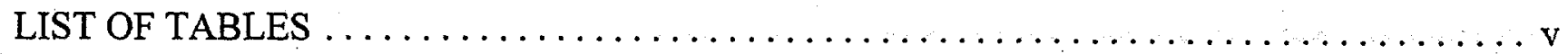

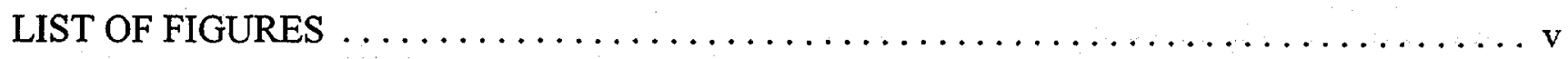

EXECUTIVE SUMMARY $\ldots \ldots \ldots \ldots \ldots \ldots \ldots \ldots \ldots \ldots \ldots \ldots \ldots \ldots \ldots$ vii

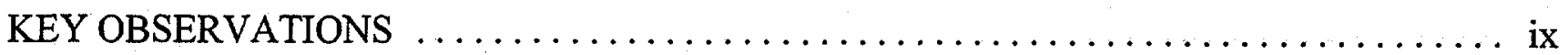

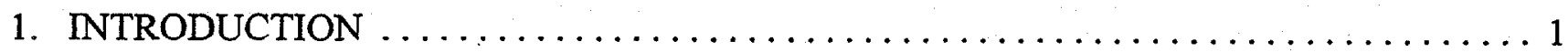

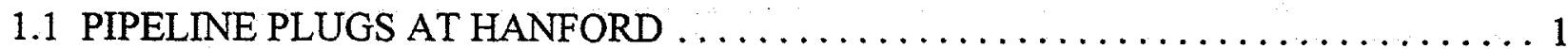

1.2 PIPELINE PLUG AT THE SAVANNAH RIVER SITE $\ldots \ldots \ldots \ldots \ldots \ldots \ldots \ldots \ldots$

1.3 PRIOR STUDIES ON SOLIDS FORMATION BY THE TANKS FOCUS AREA $\ldots \ldots, 2$

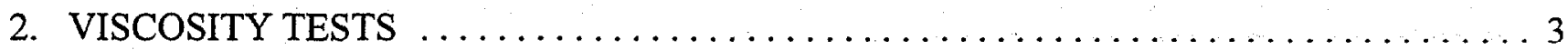

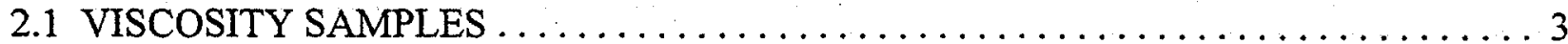

2.2 VISCOSITY DURING GRADUAL WASTE COOLING $\ldots \ldots \ldots \ldots \ldots \ldots \ldots \ldots$

2.3 VISCOSITY AFTER A SIMULATED PUMP FAILURE $\ldots \ldots \ldots \ldots \ldots \ldots \ldots 6$

2.4 VISCOSITY AFTER SIMULATED SALTCAKE DISSOLUTION $\ldots \ldots \ldots \ldots \ldots \ldots \ldots$

2.5 DISCUSSION OF THE VISCOSITY RESULTS $\ldots \ldots \ldots \ldots \ldots \ldots \ldots \ldots \ldots \ldots$

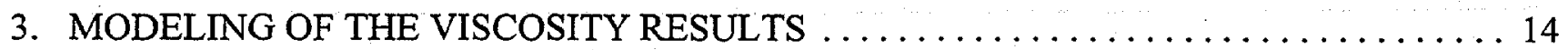

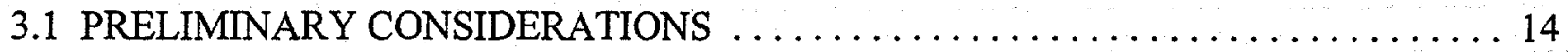

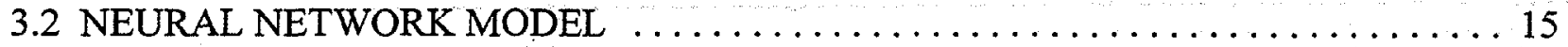

3.3 APPLICATIONS TO WASTE PROCESSING $\ldots \ldots \ldots \ldots \ldots \ldots \ldots \ldots \ldots \ldots$

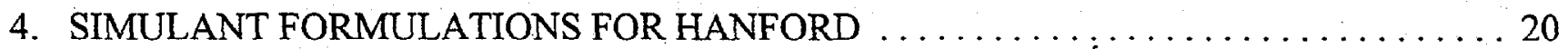

4.1 SIMULATED HIGH-NITRATE PLUG FOR THE UNIVERSITY CONTEST $\ldots \ldots \ldots 20$

4.2 SIMULANTS FOR THE TRANSFER TESTS AT AEA, FIU, AND MSU $\ldots \ldots \ldots \ldots 21$

5. RESULTS FROM THE UNIVERSITY CONTEST ON PLUG REMOVAL $\ldots \ldots \ldots \ldots .25$

5.1 TENTH ANNUAL ENVIRONMENTAL DESIGN CONTEST $\ldots \ldots \ldots \ldots \ldots \ldots \ldots 25$

5.2 MICHIGAN TECHNOLOGICAL UNIVERSITY .................... 26

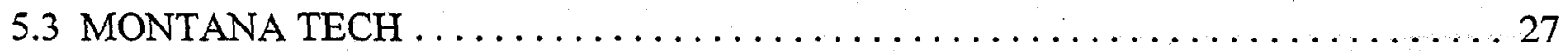

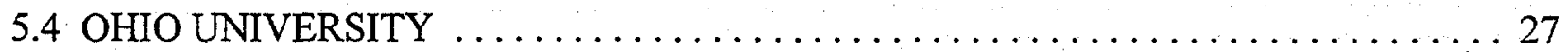

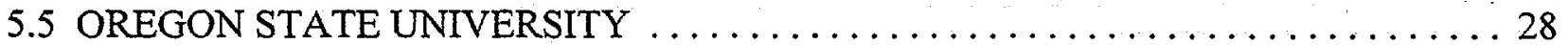

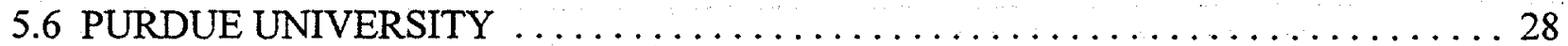

5.7 RESULTS OF THE UNIVERSITY COMPETITION ................... 29

6. PRECIPITATE FORMATION AND LINE PLUG AT SAVANNAH RIVER $\ldots \ldots \ldots \ldots 30$

6.1 SIMULANT OF THE ALUMINOSILICATE PLUG FOR THE SRS $\ldots \ldots \ldots \ldots \ldots 30$

6.2 MODELING FOR THE FORMATION OF ALUMINOSILICATES $\ldots \ldots \ldots \ldots \ldots . \ldots . \ldots$

6.3 URANIUM PRECIPITATION WITH ALUMINOSILICATES $\ldots \ldots \ldots \ldots \ldots \ldots . . \ldots 6$

6.4 MODELING ASSUMPTIONS AND PARAMETER DERIVATIONS $\ldots \ldots \ldots \ldots \ldots 38$

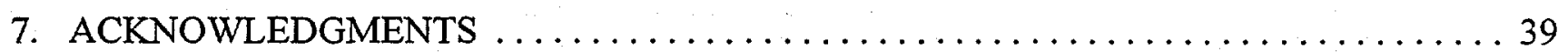

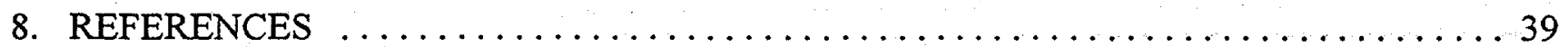




\section{LIST OF TABLES}

Table

1 High and low concentrations of the key components in the FY 1999 viscosity tests

2 Concentrations of the components in FY 2000 viscosity samples . . . . . . . . . . 5

3 Viscosity of the FY 2000 samples during gradual waste cooling $\ldots \ldots \ldots \ldots \ldots \ldots$

4 Volume of gravity-settled solids during the gradual waste cooling $\ldots \ldots \ldots \ldots \ldots$

5 Types of solids at the end of the gradual waste cooling $\ldots \ldots \ldots \ldots \ldots \ldots \ldots$

6 Simulated pump failure: initial volume of solids and final viscosity $\ldots \ldots \ldots \ldots$

7 Formulations and concentrations of the AN-103, AZ-101, and C-104 simulants . . . . . 19

8 Effects of water dilution on the viscosity of the tank $\mathrm{C}-104$ simulant . . . . . . . . 23

9 Simulants of tank U-103: initial volume of gravity-settled solids and final viscosity $\ldots 25$

10 Aluminum, silicon, and aluminosilicate solids used in the SOLGASMIX model . . . . 32

11 Results of equilibrium calculations on the SRS simulants $\ldots \ldots \ldots \ldots \ldots \ldots \ldots \ldots$

12 Solids and solubilities in the average simulant with and without uranium ....... 37

13 Derived parameters for the SOLGASMIX model at $25^{\circ} \mathrm{C} \ldots \ldots \ldots \ldots \ldots$

\section{LIST OF FIGURES}

Figure

1 Input variables, output variables, and internal variables for the classifier . . . . . . 16

2 Median result of the classifier's predictions of high and low viscosities $\ldots \ldots \ldots \ldots 18$

3 Aluminum and silicon phase diagram for the Savannah River simulants. Curves represent high hydroxide (top), average (middle), and high nitrate (bottom) simulants . . . . . . . . . . . . . . . . . 34

4 Sodium, fluoride, and sulfate solubility diagram for the Savannah River simulants. Curves represent high nitrate (top) and average (bottom) simulants 


\section{EXECUTIVE SUMMARY}

During FY 2000, key tank farm operations at Hanford and the Savannah River Site (SRS) were adversely affected by unintentional solids formations. At Hanford, the effort to saltwell pump 50,000 gal of filtered waste from tank U-103 was suspended due to a plugged pipeline. While this plug was physically removed, most of the cross-site transfer lines at Hanford can no longer be used due to plugs. At the SRS, the operations at its evaporator system were halted due to the coprecipitation of sodium aluminosilicate and sodium uranate, which contained enriched uranium. Since these pipeline plugs can lead to costly schedule delays, the tank farm operators at both sites have identified the prevention of solids formation as a high-priority need.

In response to this need, the Tanks Focus Area (TFA) assembled a team of researchers from AEA Technology, Florida International University (FIU), Mississippi State University (MSU), Oak Ridge National Laboratory (ORNL), and Savannah River Technology Center (SRTC) to evaluate various aspects of feed preparation and transport chemistry. The majority of this effort was focused on the retrieval transfers and saltwell pumping at Hanford. The FIU study clearly demonstrated that the proposed waste transfer from tank $\mathrm{AN}-101$ will not lead to a plugged pipeline even with a pump failure. Staff members at MSU have reenacted the pipeline plug that occurred during the saltwell pumping of tank SX-104. The temperature and flow conditions that can lead to a plug were measured. The MSU researchers are also using the Environmental Simulation Program (ESP) and Phoenix to simulate the test results from the flow tests at FIU and MSU. If the models can mimic the transfers, the need for extensive laboratory tests will be significantly reduced. The FIU and MSU results are discussed in detail in a companion report, ORNL/TM-2000/302. Staff members at AEA Technology have determined the particle sizes and shapes, the particle number density, the particle density, the solidphase speciation, and the density of the simulant for tank SX-104. The River Protection Project (RPP) at Hanford requested these experimental results for use in its models. Staff members at ORNL, with the assistance of the RPP, have developed simulants for tanks AN-103 and SX-104. In addition to the TFA studies, the simulant of tank SX-104 was used in a university contest on pipeline plug removal. The most effective method involved the addition of carbon dioxide to the waste. The most promising processes will be quantitatively evaluated by ORNL engineers, and the findings may lead to a pilot-scale demonstration at FIU. It should be noted that all of the effective methods used a combination of physical and chemical processes. 
ORNL staff also conducted a series of viscosity tests to determine the key factors in the formation of pipeline plugs. These factors include temperature, rate of cooling, initial ionic strength, and phosphate concentration. Waste simulants were more likely to produce high-viscosity solids if the solutions were cooled from $50^{\circ} \mathrm{C}$ to room temperature in a period of $3 \mathrm{~h}$. During gradual cooling, most of the high-viscosity solids were observed at 30 and $25^{\circ} \mathrm{C}$. A relatively small increase in the phosphate concentration from $0.04 \mathrm{M}$ to $0.06 \mathrm{M}$ led to dramatic increase in the viscosity. It should be noted that fluoride can reduce the potential for a pipeline plug caused by trisodium phosphate. In contrast, the presence of inert solids such as sodium carbonate increased the performance of the simulated plugs. The viscosity results were used as input to an artificial neural network, which can be used to identify potential problems with proposed transfers. The ORNL study also demonstrated that sludge in tank C-104 should be diluted by a minimum of $75 \%$ prior to its transfer. The viscosity of the tank C-104 simulant increased from $19 \mathrm{cP}$ to $4400 \mathrm{cP}$ as the temperature was lowered from $50^{\circ} \mathrm{C}$ to $45^{\circ} \mathrm{C}$. Finally, viscosity tests have shown that solutions from saltcake dissolution should be permitted to equilibrate for a minimum of 1 week so that the dissolution solutions can meet the waste transfer criteria.

The TFA effort on the transport chemistry at the SRS has focused on the formation of aluminosilicates in the evaporator system. Previously, ORNL researchers developed an equilibrium model for the solubility of silicate species at $25^{\circ} \mathrm{C}$. At the SRS, the solubility of amorphous silica was measured as a function of sodium hydroxide and/or sodium nitrate concentrations at 25,60 , and $95^{\circ} \mathrm{C}$. Solubilities of aluminum and silica in caustic solutions at 25,60 , and $95^{\circ} \mathrm{C}$ were also measured. The results of these solubility tests were used to increase the capabilities of the ORNL model, which will lead to the development of operating windows for the SRS evaporator system. Finally, a simulant of the evaporator plug was given to the SRS and to the Retrieval Program of the TFA. The key step in the formation of the simulated plug was the agitation of the simulant at $70^{\circ} \mathrm{C}$. 


\section{KEY OBSERVATIONS}

- Successful plug removal methods utilize a combination of chemical and physical processes.

- Key factors in the formation of Hanford plugs include temperature, rate of cooling, initial ionic strength, and phosphate concentration.

- Plugs are more likely to occur during a relatively rapid drop in temperature.

- Phosphate concentrations as low as $0.06 \mathrm{M}$ can lead to plugs.

- Fluoride can reduce the potential for a pipeline plug caused by trisodium phosphate.

- Inert solids such as sodium carbonate increased the performance of the simulated plugs.

- A preliminary version of an artificial neural network was developed to identify potential problems with proposed transfers.

- Simulant tests indicate that the sludge in tank C-104 should be diluted by a minimum of $75 \%$ prior to its transfer.

- The solutions from saltcake dissolution should be equilibrated for a minimum of 1 week prior to a transfer.

- The development of operating windows for the evaporator system at the SRS is under way.

- The key step in the formation of the simulated SRS plug was agitation at $70^{\circ} \mathrm{C}$. 
.

. 


\section{INTRODUCTION}

\subsection{PIPELINE PLUGS AT HANFORD}

Problems with pipeline plugs at Hanford have occurred throughout its tank farm system. Most cross-site transfer lines at Hanford are no longer functional due to these plugs. Waste transfers frequently led to partial line plugs, resulting in substantial amounts of water being added to the tank system in an attempt to free the lines. In response to these plugs, the Hanford tank farm developed waste acceptance criteria that a waste must pass before it can be transferred (Shekarriz et al., 1997). The criteria, which include physical properties such as viscosity, specific gravity, and percent solids, are based primarily on past operational experience. Unfortunately, the chemistry of the waste solutions was not included in the criteria even though the tank farm operators are fully aware of its importance.

Pipeline plugs have also occurred during relatively short waste transfers at Hanford. In FY 2000, the effort to saltwell pump 50,000 gal of filtered waste from tank U-103 to tank SY-102 was

delayed for several weeks due to a plugged pipeline. Attempts to locate the plug(s) determined that it had occurred in the 02-A flex and that other plugs were possible in each of the SY-farm flexes. Modifications such as larger flex jumpers and additional heat tracing were made to the transfer system. The plug was probably attributable to a reduction in the temperature of the waste in the pipeline. The waste in tank U-103 was approximately $30^{\circ} \mathrm{C}$ prior to the transfer. During tests on actual waste from tank U-103 (Herting, 1999), trisodium phosphate solids were observed at temperatures as high as $20^{\circ} \mathrm{C}$ after a $50 \%$ dilution with water. Therefore, the following precautions (Herting, 1999) were recommended during the saltwell pumping of tank U-103. First, the tank waste should not be heated prior to the transfer. Second, the waste should not be permitted to cool during the transfer. Third, the waste should be kept moving during the transfer. A previous Tanks Focus Area (TFA) study (Hunt et al., 1999) clearly demonstrated the need to maintain the temperature of the waste in this range. Even small reductions in the temperature of simulated wastes from 35 to $30^{\circ} \mathrm{C}$ and from 30 to $25^{\circ} \mathrm{C}$ led to high-viscosity solids that could easily plug a pipeline.

\subsection{PIPELINE PLUG AT THE SAVANNAH RIVER SITE}

While the Hanford tank farm has encountered numerous pipeline plugs throughout its system, the focus of concern at the Savannah River Site (SRS) has been the pipeline plug and the associated 
solid formation that occurred in its $242-16 \mathrm{H}$ evaporator system. This SRS evaporator reduces the highlevel waste stored in tank $43 \mathrm{H}$. The concentrated waste from the evaporator is permitted to flow down a 2-in.-diam line, which is called the gravity drain line (GDL), to tank $38 \mathrm{H}$. Evaporation reduces the volume of the high-salt wastes by $25-30 \%$ and the volume of the low-salt waste by $90 \%$. The high-salt wastes contain high concentrations of aluminum and very low concentrations of silicon. In contrast, the Defense Waste Processing Facility (DWPF) recycle stream, which is a low-salt waste, contains relatively high concentrations of silicon and very low concentrations of aluminum. The combination of the aluminum from the high-salt waste and silicon from the DWPF recycle stream has led to serious processing problems in the evaporator system. During the summer of 1997, the GDL became almost completely plugged with a nitrated sodium aluminosilicate, $\mathrm{Na}_{8} \mathrm{Al}_{6} \mathrm{Si}_{6} \mathrm{O}_{24}\left(\mathrm{NO}_{3}\right)_{2} \cdot 4 \mathrm{H}_{2} \mathrm{O}$ (Wilmarth et al., 1997a). Dissolution tests on the actual solids demonstrated that standard dissolution agents, such as sodium hydroxide and oxalic acid, had very little impact on the solids (Wilmarth et al., 1997a). Therefore, a high-pressure water jet was needed to physically break the GDL plug. The costs associated with removal of the actual plug and the delay in tank farm operations were on the order of several million dollars.

A recent analysis of a core sample from tank $38 \mathrm{H}$ indicated that the solids contained $6 \%$ uranium, which had been enriched to $2.4 \%$. The high concentration of uranium had not been anticipated due to the very low concentration of uranium in the feed tank for the evaporator. Due to the high concentration of enriched uranium in the solids, an investigation is under way to determine if the solids can exceed the criticality limits. If so, then the evaporator operations will be suspended. The presence of sodium diuranate could limit the treatment options for the aluminosilicates.

\subsection{PRIOR STUDIES ON SOLIDS FORMATION BY THE TANKS FOCUS AREA}

During FY 1999, the TFA evaluated several different aspects of solids formation (Hunt et al., 1999). The initial step in this effort was to review relevant documents on Hanford pipeline plugs, which were recently summarized (Colton et al., 1998). Unfortunately, very few of the pipeline plugs were retrieved and characterized; as a result, only sodium orthophosphate needle-like crystals are known to have plugged a Hanford pipeline (Herting, 1980). The analysis of these previous studies led to the identification of seven chemical components that could potentially impact the viscosity of Hanford tank wastes. The components are aluminate/alumina, fluoride, hydroxide, nitrate, phosphate, 
silicon, and sulfate. While sodium and water are also present in each of the samples, they were not explicitly included as variables, except when dilution was considered. The best-basis inventories were used to determine the appropriate concentration of each component. A series of viscosity tests was performed so that the significance of each of seven components could be determined. This FY 1999 study indicated that the phosphate concentration, initial ionic strength, and temperature must be controlled to prevent pipeline plugs. In addition to the waste transfer, solids formation can occur during Enhanced Sludge Washing (ESW). In FY 1997, it was shown that natrophosphate gels and particles (Beahm et al., 1998) are formed as the hot leach solutions from the ESW process are permitted to cool. Therefore, the initial formulation of the chemical simulant of a Hanford pipeline plug contained both sodium orthophosphate and natrophosphate. The simulant consisted of $3 M$ sodium hydroxide and/or sodium nitrate, $0.9 \mathrm{M}$ trisodium phosphate, and $0.3 \mathrm{M}$ sodium fluoride. The formulation without the sodium nitrate was used in a university contest on plug removal methods.

In addition to the problems due to phosphates, the formation of aluminosilicates can adversely impact waste pretreatment and transport activities. In FY 1998 (Hunt et al., 1998) and FY 1999 (Hunt et al., 1999) studies, insoluble aluminosilicates apparently formed during the hot caustic leaching. This phenomenon could significantly reduce the performance of the ESW process at Hanford. The problems due to the formation of nitrated sodium aluminosilicate at the SRS were described earlier. These problems with aluminosilicates led to the development of an equilibrium model on the solubility of silicate species at $25^{\circ} \mathrm{C}$ (Hunt et al., 1999). This model is the initial step in the development of operating windows for tank operations at Hanford and the SRS.

\section{VISCOSITY TESTS}

\subsection{VISCOSITY SAMPLES}

The FY 1999 viscosity samples and tests (Hunt et al., 1999) were designed to determine the significance of aluminum, fluoride, hydroxide, nitrate, phosphate, silicate, and sulfate in the formation of Hanford pipeline plugs. A two-level seven-factor partial factorial, which utilized only two concentrations for each components, was used to determine the formulation of each sample. The bestbasis inventories of the Hanford tanks were analyzed to determine reasonable high and low concentrations for each of the seven components. Nearly all of these concentrations were reduced by 
a factor of 2 in order to produce viscosity samples with reasonable specific gravities, which can be as high as $1.4 \mathrm{~g} / \mathrm{mL}$. The high and low concentrations for the FY 1999 tests are shown in Table 1. Whenever possible, these high and low concentrations were used in the FY 2000 samples, which were designed to provide additional input into operating windows. The compositions of the FY 2000 viscosity samples are presented in Table 2 . Three different sets of viscosity samples were prepared. Previous viscosity results were used to select most of the concentrations of the samples in Sets A and B. The formulations in Set $\mathrm{C}$ were chosen to determine the impact of carbonate and to test the simulants for Hanford tanks AN-104, AZ-101, SX-104, and U-103 for use by AEA Technologies, Florida International University (FIU), and Mississippi State University (MSU). Sodium aluminate or aluminum hydroxide, sodium carbonate, sodium fluoride, sodium hydroxide, sodium nitrate, sodium nitrite, trisodium phosphate, sodium silicate, sodium sulfate, and deionized water were used in the sample preparation. The highest specific gravity in these samples was $1.5 \mathrm{~g} / \mathrm{mL}$.

Table 1. High and low concentrations of the key components in the FY 1999 viscosity tests (Components in $\mathrm{mol} / \mathrm{L}$ )

\begin{tabular}{cccccccc}
\hline & $\mathrm{Al}(\mathrm{OH})_{4}^{-}$ & $\mathrm{F}^{-}$ & $\mathrm{OH}^{-}$ & $\mathrm{NO}_{3}^{-}$ & $\mathrm{PO}_{4}{ }^{3-}$ & $\mathrm{SiO}_{2}$ & $\mathrm{SO}_{4}{ }^{2-}$ \\
\hline High & 1.0 & 0.2 & 4.0 & 4.0 & 0.5 & 0.25 & 0.25 \\
Low & 0.1 & 0.01 & 1.0 & 1.0 & 0.025 & 0.025 & 0.025 \\
\hline
\end{tabular}

\subsection{VISCOSITY DURING GRADUAL WASTE COOLING}

After the 20-mL samples were prepared, they were placed in an Aquatherm water-bath shaker. The temperature of the samples was maintained at $80^{\circ} \mathrm{C}$ for 2 weeks prior to the initial viscosity measurements. The samples were rotated at a rate of $100 \mathrm{rpm}$. However, the rotation did not prevent the solids from settling to the bottom of the bottle. Each sample was shaken by hand to resuspend all of the solids in the sample before $16 \mathrm{~mL}$ of the sample was transferred into the preheated small-sample adapter for the Brookfield DV-III rheometer. The sample was then permitted to equilibrate for $15 \mathrm{~min}$. For each sample, two viscosity tests were performed in an effort to determine the effects of shear rate and time. During the tests, the shear rate was varied from $12 \mathrm{~s}^{-1}$ to $122 \mathrm{~s}^{-1}$ to $12 \mathrm{~s}^{-1}$. The particular shear rate was maintained for a period of $2 \mathrm{~min}$ before it was increased or decreased by $12 \mathrm{~s}^{-1}$. In the timed tests, a shear rate of $61 \mathrm{~s}^{-1}$ was applied to the sample for $5 \mathrm{~min}$. If a sample was too viscous, a 
Table 2. Concentrations of the components in FY 2000 viscosity samples ${ }^{a}$ (Components in mol/L)

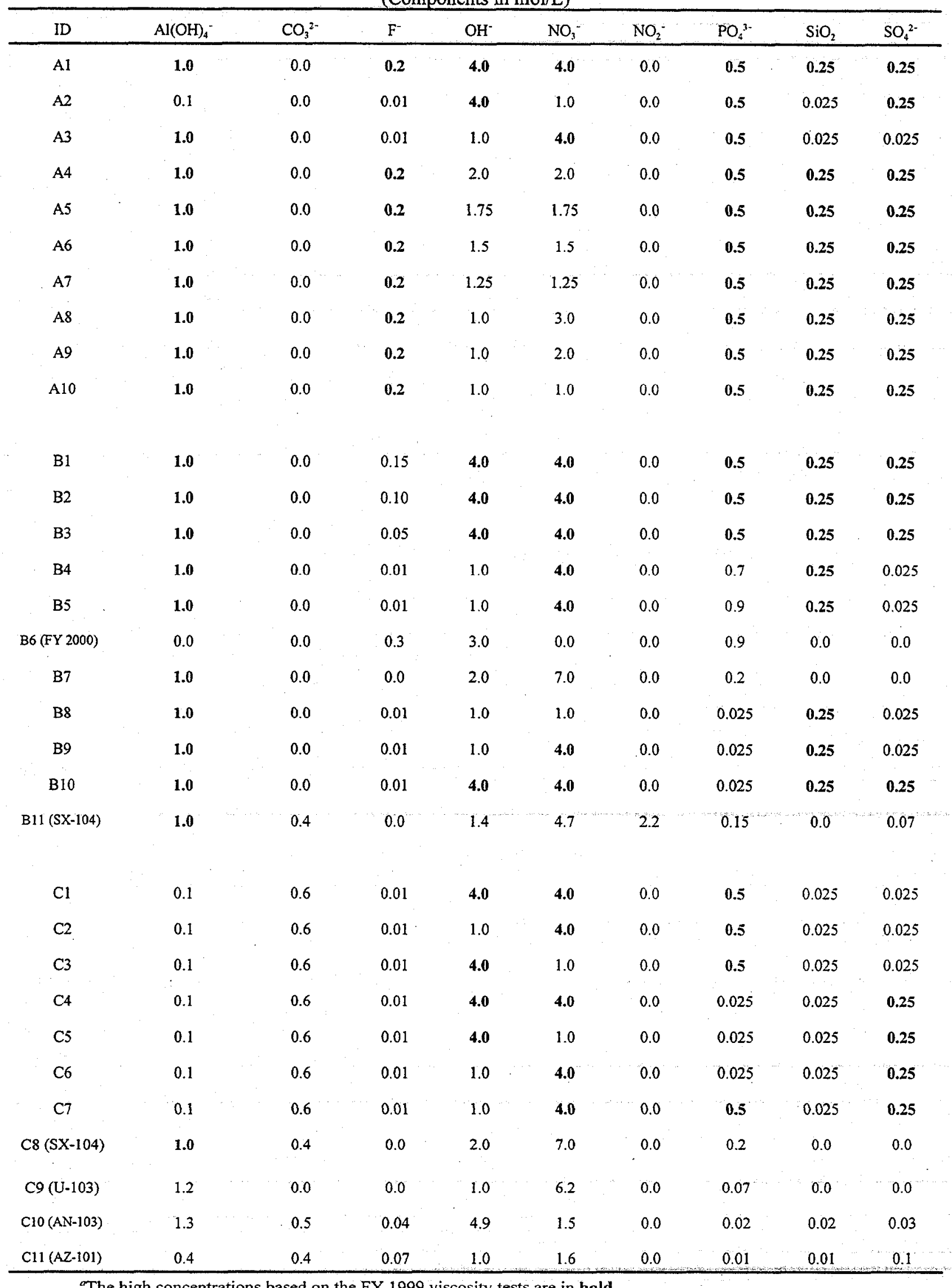

${ }^{\circ}$ The high concentrations based on the FY 1999 viscosity tests are in bold. 
lower shear rate was used. The viscosity results from the 5-min tests are presented in Table 3 . At the end of the $80^{\circ} \mathrm{C}$ tests, the samples were allowed to equilibrate at $65^{\circ} \mathrm{C}$ for 1 week prior to the next set of viscosity measurements. At $65^{\circ} \mathrm{C}$, all of the viscosity samples contained solids, and the height of the settled solids in each sample was measured. The height results were converted to the volume percent of gravity-settled solids, which are presented in Table 4 . The volume below the spindle in the small-sample adapter is $2.6 \mathrm{~mL}$, which is $16 \%$ of the total sample volume. Since solids settled into this void space during most of the viscosity tests, the viscosity measurements should be considered to be minimum values. The 1 -week equilibration period was repeated at $50^{\circ} \mathrm{C}$. After the $50^{\circ} \mathrm{C}$ tests, the equilibration period for the next lower temperature was reduced to 3.5 days and the temperature was decreased in increments of $5^{\circ} \mathrm{C}$ until the temperature reached $10^{\circ} \mathrm{C}$. At the conclusion of the viscosity tests, the samples were permitted to equilibrate at room temperature, and they were then evaluated for particle type and adhesiveness to other sample particles and to metal. The results of this evaluation are presented in Table 5.

\subsection{VISCOSITY AFTER A SIMULATED PUMP FAILURE}

After the types of solids were evaluated, the samples were reheated to $50^{\circ} \mathrm{C}$ for approximately 1 week. The River Protection Project (RPP) at Hanford has set $50^{\circ} \mathrm{C}$ as the minimum operating temperature for its retrieval transfers, while the temperature for its saltwell pumping operations is not controlled. After the equilibration period, the height of the solids was measured, and $16 \mathrm{~mL}$ of the hot sample was transferred into the rheometer's small-sample adapter, which was also heated to $50^{\circ} \mathrm{C}$. The heat source to the adapter was shut off, and the sample was permitted to cool to ambient temperature, which was typically $17-20^{\circ} \mathrm{C}$, in an effort to simulate a pump failure. The initial rate of cooling was slightly more than $0.5^{\circ} \mathrm{C} / \mathrm{m}$, and the cooldown period was approximately $3 \mathrm{~h}$. Two viscosity tests were then performed in an effort to determine the effects of shear rate and time. For the tests on simulated pump failures at $50^{\circ} \mathrm{C}$, the viscosity measurements at a shear rate of $61 \mathrm{~s}^{-1}$ and the volume percent of settled solids at $50^{\circ} \mathrm{C}$ are presented in Table 6.

Additional tests on simulated pump failure were performed. The samples were heated at $70^{\circ} \mathrm{C}$ for 1 week. At the end of the equilibration period, the volume percent of the gravity-settled solids was determined, and most of the hot sample was transferred into the rheometer's small-sample adapter, which was also heated to $70^{\circ} \mathrm{C}$. The temperature of the water bath, which controls the temperature of the small-sample adapter, was reduced to $40^{\circ} \mathrm{C}$. The initial rate of cooling was 
Table 3. Viscosity of the FY 2000 samples during gradual waste cooling (Viscosity in CP)

\begin{tabular}{|c|c|c|c|c|c|c|c|c|c|c|c|}
\hline ID & $80^{\circ} \mathrm{C}$ & $65^{\circ} \mathrm{C}$ & $50^{\circ} \mathrm{C}$ & $45^{\circ} \mathrm{C}$ & $40^{\circ} \mathrm{C}$ & $35^{\circ} \mathrm{C}$ & $30^{\circ} \mathrm{C}$ & $25^{\circ} \mathrm{C}$ & $20^{\circ} \mathrm{C}$ & $15^{\circ} \mathrm{C}$ & $10^{\circ} \mathrm{C}$ \\
\hline Al & 4.8 & 5.1 & 3.4 & 3.5 & 3.5 & 3.2 & 3.3 & 3.3 & 3.6 & 3.8 & 3.7 \\
\hline $\mathrm{A} 2$ & 1.4 & 2.1 & 2.3 & 2.3 & 2.1 & 2.7 & 6.1 & ${\underline{187^{a}}}^{a}$ & 2.8 & 2.3 & 2.3 \\
\hline $\mathrm{A} 3$ & 1.5 & 2.2 & 2.2 & 2.2 & 1.9 & 1.9 & $\underline{284^{\prime \prime}}$ & $\underline{200}^{4}$ & 2.3 & 2.2 & 2.2 \\
\hline $\mathrm{A} 4$ & 2.8 & 2.8 & 2.7 & 2.2 & 2.0 & 1.9 & 2.2 & 2.2 & 2.4 & 2.7 & 2.7 \\
\hline A5 & 2.7 & 2.5 & 2.3 & 2.5 & 2.3 & 2.3 & 2.6 & 2.8 & 3.1 & 3.3 & 3.2 \\
\hline A6 & 2.6 & 2.4 & 2.1 & 2.2 & 2.1 & 2.1 & 2.3 & 2.3 & 2.4 & 2.5 & 2.7 \\
\hline A7 & 2.6 & 2.4 & 2.1 & 2.2 & 2.1 & 2.3 & 2.4 & 2.5 & 2.8 & 3.1 & 3.0 \\
\hline A8 & 4.9 & 4.6 & 3.6 & 3.0 & 2.3 & 2.4 & 2.5 & 2.6 & 3.5 & 2.9 & 2.9 \\
\hline A. 9 & 4.6 & 3.6 & 3.3 & 3.0 & 2.3 & 2.4 & 2.5 & 2.4 & 3.2 & 2.9 & 2.9 \\
\hline A10 & 2.5 & 2.3 & 2.3 & 2.4 & 2.2 & 2.3 & 2.3 & 2.3 & 2.9 & 2.9 & 2.9 \\
\hline B1 & 3.1 & 3.4 & 3.6 & 4.2 & 3.8 & 3.7 & 3.5 & 3.8 & 3.8 & 4.3 & 4.6 \\
\hline B2 & 3.0 & 3.4 & 3.2 & 2.8 & 2.8 & 2.8 & 2.8 & 3.2 & 3.3 & 3.3 & 3.8 \\
\hline B3 & 3.5 & 3.7 & 3.3 & 6.6 & 4.6 & 4.6 & 4.6 & 4.7 & 4.8 & 4.8 & 5.6 \\
\hline $\mathrm{B} 4$ & 2.5 & 2.2 & 2.1 & 1.8 & 2.2 & 1.7 & 2.1 & $82^{h}$ & $\underline{53}^{h}$ & 2.2 & 2.5 \\
\hline B5 & 2.5 & 1.8 & $\underline{110^{h}}$ & 2.4 & 1.8 & 1.7 & 2.3 & 1.6 & 2.0 & 2.0 & 2.3 \\
\hline B6 & 1.1 & 1.3 & 1.3 & 1.3 & 1.4 & 1.3 & 1.5 & 1.7 & 1.9 & 2.0 & 2.3 \\
\hline $\mathrm{B7}$ & 2.2 & 2.5 & 2.6 & 2.4 & 2.6 & 2.6 & 2.7 & 3.0 & 3.1 & 3.4 & 3.9 \\
\hline B8 & $<1$ & $<1$ & 1.1 & 1.1 & 1.2 & 1.2 & 1.4 & 1.6 & 1.7 & 1.9 & 2.4 \\
\hline $\mathrm{B} 9$ & 1.4 & 1.4 & 1.6 & 1.6 & 1.7 & 1.7 & 1.9 & 2.1 & 2.0 & 2.5 & 2.8 \\
\hline B10 & 2.2 & 2.2 & 2.7 & 2.5 & 2.7 & 2.8 & 3.0 & 3.2 & 3.9 & 4.4 & 5.3 \\
\hline B11 & 2.8 & 3.2 & 3.7 & 3.9 & 4.6 & 4.6 & 3.9 & 4.4 & 4.2 & 4.6 & 5.0 \\
\hline $\mathrm{Cl}$ & .2 .6 & 2.9 & 3.3 & 3.3 & 3.0 & 3.3 & 3.1 & 3.1 & 3.2 & 3.7 & 4.7 \\
\hline $\mathrm{C} 2$ & 1.6 & 2.0 & 2.4 & 2.4 & 2.5 & 2.5 & 2.8 & 3.0 & 3.0 & 3.4 & 4.0 \\
\hline $\mathrm{C} 3$ & 1.9 & 2.1 & ${\underline{2400^{c}}}^{c}$ & ${\underline{3300^{c}}}^{\circ}$ & ${\underline{3500^{c}}}^{c}$ & ${\underline{3300^{\circ}}}^{\circ}$ & $3500^{c}$ & $\underline{2400^{\circ}}$ & ${\underline{1700^{c}}}^{c}$ & 3.4 & 4.1 \\
\hline $\mathrm{C} 4$ & 1.6 & 2.1 & 2.9 & 3.1 & 3.3 & 3.9 & 4.3 & 4.8 & 5.6 & 6.9 & 8.4 \\
\hline $\mathrm{Cs}$ & 1.3 & 1.6 & 2.2 & 2.3 & 2.4 & 2.6 & 2.7 & 2.9 & 3.4 & 3.9 & 4.7 \\
\hline $\mathrm{C} 6$ & 1.3 & 1.4 & 1.8 & 2.0 & 2.0 & 2.1 & 2.2 & 2.6 & 2.9 & 3.3 & 3.9 \\
\hline $\mathrm{C} 7$ & 1.7 & 2.3 & 2.8 & 2.8 & 2.4 & 2.5 & 2.6 & 2.7 & 3.0 & 3.1 & 3.5 \\
\hline $\mathrm{C} 8$ & 2.5 & 2.7 & 3.0 & 3.0 & 3.0 & 3.3 & 3.5 & 3.6 & 4.2 & 4.9 & 5.9 \\
\hline $\mathrm{CP}$ & 1.7 & 1.8 & 2.2 & 2.2 & 2.3 & 2.7 & 2.7 & 3.0 & 3.5 & 4.2 & 4.9 \\
\hline $\mathrm{Clo}$ & 2.4 & 3.6 & 4.0 & 4.0 & 4.1 & 4.2 & 4.6 & 5.8 & 6.0 & 7.2 & 7.3 \\
\hline $\mathrm{Cl1}$ & 0.8 & 0.8 & 1.0 & 1.1 & 1.2 & 1.2 & 1.3 & 1.5 & 1.7 & 1.9 & 2.1 \\
\hline
\end{tabular}


Table 4. Volume of gravity-settled solids during the gradual waste cooling

\begin{tabular}{|c|c|c|c|c|c|c|c|c|c|c|}
\hline ID & $65^{\circ} \mathrm{C}$ & $50^{\circ} \mathrm{C}$ & $45^{\circ} \mathrm{C}$ & $40^{\circ} \mathrm{C}$ & $35^{\circ} \mathrm{C}$ & $30^{\circ} \mathrm{C}$ & $25^{\circ} \mathrm{C}$ & $20^{\circ} \mathrm{C}$ & $15^{\circ} \mathrm{C}$ & $10^{\circ} \mathrm{C}$ \\
\hline $\mathrm{Al}$ & 15 & 25 & 25 & 20 & 15 & 25 & 25 & 40 & 35 & 20 \\
\hline $\mathrm{A} 2$ & $<5$ & $<5$ & $<5$ & $<5$ & $<5$ & $s$ & 10 & 45 & 30 & 20 \\
\hline $\mathrm{A} 3$ & $<5$ & $<5$ & $<5$ & $<5$ & $<5$ & 5 & 10 & 50 & 35 & 30 \\
\hline $\mathrm{A} 4$ & 5 & 25 & 20 & 15 & 15 & 20 & 20 & 30 & 25 & 25 \\
\hline A5 & 15 & 35 & 15 & 15 & 20 & 20 & 20. & 30 & 25 & 25 \\
\hline $\mathrm{A} 6$ & 15 & 35 & 20 & 15 & 20 & 25 & 25 & 25 & 25 & 25 \\
\hline A7 & 10 & 30 & 25 & 25 & 25 & 25 & 20 & 25 & 25 & 25 \\
\hline A8 & 10 & 30 & 25 & 25 & 25 & 25 & 25 & 25 & 25 & 25 \\
\hline A9 & 10 & 25 & 25 & 20 & 20 & 35 & 30 & 35 & 20 & 20 \\
\hline AlO & 5 & 25 & 20 & 20 & 20 & 25 & 25 & 30 & 20 & 20 \\
\hline B1 & 10 & 15 & 25 & 35 & 35 & 30 & 25 & 20 & 20 & 20 \\
\hline B2 & 15 & 20 & 25 & 25 & 30 & 30 & 25 & 25 & 30 & 25 \\
\hline B3 & 20 & 30 & 30 & 35 & 40 & 35 & 30 & 25 & 25 & 30 \\
\hline B4 & 5 & 15 & 25 & 40 & 25 & 30 & 25 & 25 & 25 & 25 \\
\hline B5 & 10 & 15 & 40 & 35 & 40 & 35 & 30 & 30 & 25 & 25 \\
\hline B6 & 20 & 20 & 30 & 25 & 30 & 25 & 25 & 30 & 30 & 20 \\
\hline B7 & 0 & $<5$ & $<5$ & $<5$ & 10 & 5 & 5 & 15 & 15 & 15 \\
\hline B8 & 10 & 10 & 10 & 15 & 15 & 15 & 15 & 15 & 15 & 10 \\
\hline B9 & 10 & 20 & 20 & 20 & 20 & 15 & 20 & 20 & 15 & 20 \\
\hline B10 & 10 & 15 & 10 & 10 & 10 & 10 & 10 & 15 & 15 & 5 \\
\hline B11 & 0 & $<5$ & $<5$ & $<5$ & $<5$ & $<5$ & $<5$ & 5 & 5 & 5 \\
\hline $\mathrm{Cl}$ & $<5$ & 5 & 25 & 30 & 30 & 35 & 35 & 20 & 20 & 25 \\
\hline $\mathrm{C} 2$ & 10 & 20 & 20 & 35 & 35 & 35 & 40 & 30 & 30 & 30 \\
\hline $\mathrm{C} 3$ & 10 & 15 & 40 & 35 & 35 & 35 & 30 & 25 & 25 & 25 \\
\hline $\mathrm{C} 4$ & 10 & 10 & 10 & 10 & 10 & 10 & 15 & 15 & 15 & 15 \\
\hline $\mathrm{C} 5$ & 10 & 10 & 10 & 10 & 10 & 10 & 10 & 10 & 10 & 20 \\
\hline C6 & $<5$ & 5 & 15 & 15 & 15 & 15 & 15 & 15 & 15 & 15 \\
\hline $\mathrm{C} 7$ & $<5$ & 10 & 15 & 25 & 25 & 25 & 25 & 20 & 20 & 25 \\
\hline $\mathrm{C} 8$ & $<5$ & $<5$ & $<5$ & $<5$ & 10 & 10 & 15 & 15 & 15 & 20 \\
\hline $\mathrm{C} 9$ & 20 & 20 & 20 & 20 & 20 & 15 & 15 & 20 & 20 & 20 \\
\hline $\mathrm{ClO}$ & 5 & 5 & 10 & 10 & 10 & 10 & 10 & 10 & 10 & 10 \\
\hline $\mathrm{C} 11$ & 10 & 10 & 10 & 10 & 10 & 10 & 10 & 10 & 10 & 10 \\
\hline
\end{tabular}


Table 5. Types of solids at the end of the gradual waste cooling

\begin{tabular}{|c|c|c|c|}
\hline ID & Particle type & Adhesive to other particles & Adhesive to metal \\
\hline A1 & Large crystals in packed powder & Yes & No \\
\hline A2 & Packed powder & Yes & No \\
\hline A3 & Crystals in gel & Yes & No \\
\hline A4 & Small crystals in packed powder & Yes & Yes \\
\hline A5 & Small crystals in packed powder & Yes & Yes \\
\hline A6 & Fine crystals in packed powder & Yes & Yes \\
\hline A7 & Small crystals in packed powder & Yes & Yes \\
\hline A8 & Packed powder & Yes & Yes \\
\hline A9 & Small crystals in packed powder & Yes & Yes \\
\hline A10 & Fine crystals in packed powder & Yes & Yes \\
\hline B1 & Needle crystals in gel & Yes & No \\
\hline B2 & Needle crystals in gel & Yes & No \\
\hline B3 & Needle crystals in gel & Yes & No \\
\hline B4 & Small crystals and needle crystals in gel & Yes & Yes \\
\hline B5 & Small crystals in gel & Yes & Yes \\
\hline B6 & Needle crystals in gel & Yes & No \\
\hline B7 & Fine crystals and needle crystals in gel & Yes & Yes \\
\hline B8 & Packed powder & Yes & Yes \\
\hline B9 & Fine powder & Yes & Yes \\
\hline B10 & Fine powder & Yes & Yes \\
\hline B11 & Large crystals & Yes & No \\
\hline $\mathrm{Cl}$ & Crystals and needle crystals in gel & Yes & Yes \\
\hline $\mathrm{C} 2$ & $\begin{array}{l}\text { Single mass of large crystals and large } \\
\text { needle crystals }\end{array}$ & Yes & No \\
\hline $\mathrm{C} 3$ & $\begin{array}{l}\text { Single mass of large crystals and large } \\
\text { needle crystals }\end{array}$ & Yes & No \\
\hline $\mathrm{C} 4$ & Fine powder & Yes & No \\
\hline $\mathrm{Cs}$ & Fine powder & Slightly & No \\
\hline $\mathrm{C} 6$ & Fine powder & Slightly & No \\
\hline $\mathrm{C} 7$ & Small crystals and needle crystals in gel & Yes & Yes \\
\hline $\mathrm{C} 8$ & Fine powder & Slightly & Yes \\
\hline $\mathrm{C} 9$ & Fine powder & Slightly & Yes \\
\hline $\mathrm{C} 10$ & Packed powder & Yes. & Yes \\
\hline $\mathrm{C} 11$ & Packed powder & Yes & No \\
\hline
\end{tabular}


Table 6. Simulated pump failure: initial volume of solids and final viscosity

\begin{tabular}{|c|c|c|c|c|c|c|}
\hline Sample ID & $\begin{array}{l}\text { Viscosity (cP): } \\
70 \text { to } 40^{\circ} \mathrm{C}\end{array}$ & $\begin{array}{l}\text { Volume percent } \\
\text { of solids: } 70^{\circ} \mathrm{C}\end{array}$ & $\begin{array}{l}\text { Viscosity (cP): } \\
60 \text { to } 30^{\circ} \mathrm{C}\end{array}$ & $\begin{array}{l}\text { Volume percent of } \\
\text { solids: } 60^{\circ} \mathrm{C}\end{array}$ & $\begin{array}{l}\text { Viscosity }(\mathrm{cP}): \\
50 \text { to } 18^{\circ} \mathrm{C}\end{array}$ & $\begin{array}{l}\text { Volume percent of } \\
\text { solids: } 50^{\circ} \mathrm{C}\end{array}$ \\
\hline $\mathrm{Al}$ & 1.9 & 10 & 2.4 & 5 & $\underline{16}^{\circ}$ & 20 \\
\hline $\mathrm{A} 2$ & 1.4 & 0 & 1.6 & $<5$ & $\underline{53}^{\circ}$ & 15 \\
\hline $\mathrm{A} 3$ & 1.4 & 5 & 1.5 & 5 & 1.8 & 15 \\
\hline A4 & 1.5 & 10 & 1.9 & 15 & 2.3 & 25 \\
\hline A5 & 1.6 & 15 & 1.8 & 15 & 2.1 & 30 \\
\hline A6 & 1.7 & 15 & 1.7 & 10 & 2.8 & 30 \\
\hline A7 & 1.5 & 15 & 1.7 & 20 & 2.3 & 30 \\
\hline A8 & 1.4 & 5 & 1.7 & 20 & $\underline{24^{\prime \prime}}$ & 25 \\
\hline A9 & 1.6 & 15 & 2.0 & 15 & 2.5 & 30 \\
\hline A 10 & 1.8 & 20 & 1.7 & 15 & 2.2 & 25 \\
\hline $\mathrm{B} 1$ & 2.3 & 15 & 2.7 & 15 & 5.8 & 20 \\
\hline B2 & 2.2 & 10 & 2.7 & 10 & 6.1 & 20 \\
\hline B3 & 2.5 & 10 & $\underline{484^{b}}$ & 10 & $\underline{56}^{a}$ & 15 \\
\hline B4 & 1.7 & 15 & $\underline{2810^{c}}$ & 15 & ${\underline{834^{d}}}^{.}$ & 15 \\
\hline $\mathrm{B} 5$ & 1.7 & 10 & ${\underline{1450^{\circ}}}^{\circ}$ & 10 & $\underline{919^{\prime \prime}}$ & 15 \\
\hline B6 & 1.5 & $<5$ & 2.1 & $<5$ & $\geq 6000^{\circ}$ & 25 \\
\hline B7 & 1.9 & $<5$ & 2.3 & $<5$ & $\underline{31}^{\mu}$ & 10 \\
\hline $\mathrm{B} 8$ & 1.2 & 10 & 1.4 & 15 & 1.7 & 20 \\
\hline B9 & 1.5 & 5 & 1.8 & 15 & 1.9 & 20 \\
\hline $\mathrm{B} 10$ & 2.6 & 5 & 2.8 & 25 & 3.3 & 15 \\
\hline $\mathrm{B} 11$ & 2.2 & $<5$ & 2.3 & 5 & 3.3 & $<5$ \\
\hline $\mathrm{Cl}$ & 2.0 & 5 & 2.7 & 5 & $\underline{264^{b}}$ & 5 \\
\hline $\mathrm{C} 2$ & 2.1 & 10 & 2.5 & 10 & $\underline{139^{h}}$ & 15 \\
\hline $\mathrm{C} 3$ & 2.0 & 5 & 1.9 & 5 & $\geq 6000^{c}$ & 10 \\
\hline $\mathrm{C} 4$ & 2.6 & 10 & 2.8 & 10 & 3.5 & 10 \\
\hline $\mathrm{C} 5$ & 1.7 & 10 & 2.0 & 10 & 2.5 & 10 \\
\hline $\mathrm{C} 6$ & 1.7 & 5 & 2.0 & 5 & 2.3 & 5 \\
\hline $\mathrm{C} 7$ & 2.2 & 10. & 2.7 & 10 & $\underline{153^{h}}$ & 10. \\
\hline $\mathrm{C} 8$ & 2.4 & $<5$ & 2.5 & 5 & $\underline{37^{u}}$ & 5 \\
\hline $\mathrm{Cg}$ & 2.2 & 10 & 2.2 & 15 & $2.9^{\circ}$ & 20 \\
\hline $\mathrm{C} 10$ & 2.6 & 5 & 3.2 & 10 & 4.1 & 10 \\
\hline $\mathrm{Cl1}$ & 1.1 & 10 & 1.3 & 10 & 1.8 & 10 \\
\hline $\begin{array}{l}{ }^{a} \text { She } \\
\text { "She } \\
\text { cShe } \\
\text { dShe }\end{array}$ & $\begin{array}{l}\text { ate of } 12 \mathrm{~s}^{-1} \\
\text { ate of } 1 \mathrm{~s}^{-1} \\
\text { ate of } 0.1 \mathrm{~s}^{-1} \\
\text { ate of } 0.6 \mathrm{~s}^{-1}\end{array}$ & & . & & & \\
\hline
\end{tabular}


$1^{\circ} \mathrm{C} / \mathrm{m}$, and the cooldown took approximately $1 \mathrm{~h}$. After the sample had reached $40^{\circ} \mathrm{C}$ and been maintained at that temperature for $2 \mathrm{~h}$, the viscosity measurements were made. The samples were then heated to $60^{\circ} \mathrm{C}$ for 1 week. After the equilibrated samples were transferred to the rheometer, the samples were cooled to $30^{\circ} \mathrm{C}$ for $2 \mathrm{~h}$ and the final viscosity measurements were then made. For the simulated pump failure at $70^{\circ} \mathrm{C}$ and $60^{\circ} \mathrm{C}$, the viscosity measurements at a shear rate of $61 \mathrm{~s}^{-1}$ and the volume of settled solids at higher temperatures are shown in Table 6.

\subsection{VISCOSITY AFTER SIMULATED SALTCAKE DISSOLUTION}

The chemical compositions of the viscosity samples are comparable to the expected waste compositions after saltcake dissolution at Hanford. Therefore, the RPP inquired if these viscosity results could be used to predict the properties of the aqueous solutions from the saltcake dissolution process. In response, the $\mathrm{C} 1$ and $\mathrm{C} 2$ samples, which have been equilibrated at $35^{\circ} \mathrm{C}$, were evaporated to dryness at $85^{\circ} \mathrm{C}$ in order to simulate dry saltcake samples. Next, the dried samples were restored to their original volumes through the addition of deionized water, and the rehydrated samples were permitted to equilibrate at $35^{\circ} \mathrm{C}$. After $24 \mathrm{~h}$, the rehydrated samples contained less than half of their original solids and the sample viscosities had increased from $3 \mathrm{cP}$ to $340-450 \mathrm{cP}$. The viscosity of one sample continued to increase to $3100 \mathrm{cP}$. In 7-9 days after the rehydration, the viscosity and the solids content for the rehydrated samples returned to their values prior to the evaporation. These results indicate that the viscosity results from this study can be directly applied to saltcake dissolution if the dissolution solution is permitted to equilibrate for a minimum of 1 week. It is expected that this equilibration period will be needed so the dissolution solution can meet the waste transfer criteria of the RPP.

\subsection{DISCUSSION OF THE VISCOSITY RESULTS}

The FY 1999 study (Hunt et al., 1999) on the formation of pipeline plugs at Hanford indicated that the phosphate concentration, initial ionic strength, and temperature were the primary factors in the plug formation. These FY 2000 viscosity tests were designed to further evaluate these primary components and to identify secondary factors. For example, 5 of the 16 samples, which 
contained a minimum phosphate concentration of $0.5 \mathrm{M}$, formed high-viscosity solids during the gradual waste-cooling tests. The fluoride concentration in the high-viscosity samples was $0.01 M$, while the other 11 contained a minimum fluoride concentration of $0.05 \mathrm{M}$. This result indicates that small quantities of fluoride could be used to prevent pipeline plugs. However, the effectiveness of fluoride to prevent plugs can be significantly reduced if the temperature is not adequately controlled. When the samples with a minimum phosphate concentration of $0.5 \mathrm{M}$ were cooled from $50^{\circ} \mathrm{C}$ to $18^{\circ} \mathrm{C}$, the number of samples with high-viscosity solids increased to nine. Therefore, the fluoride concentration and the rate of cooling are important factors in the formation of pipeline plugs. It is apparent that the solids formation is significantly influenced by the rate and magnitude of the cooling. Analyses of the solids have shown that the primary phosphate solids are trisodium phosphate $\left(\mathrm{Na}_{3} \mathrm{PO}_{4}\right)$ and natrophosphate $\left(2 \mathrm{Na}_{3} \mathrm{PO}_{4} \cdot \mathrm{NaF} \cdot 19 \mathrm{H}_{2} \mathrm{O}\right)$. Most of the pipeline plugs at Hanford (Colton et al., 1998) are believed to be due to the trisodium phosphate needle crystals. Since the number of high-viscosity samples nearly doubled after the rapid cooldown, it is apparent that the rapid cooldown will initially increase the ratio of trisodium phosphate to natrophosphate. However, the ratio of trisodium phosphate to natrophosphate will decrease as the equilibration period is increased, and the strength of the plug should be reduced. Therefore, the length of time after the formation of the plug can be a key variable, and it may be advisable for the RPP to wait a few weeks before attempting plug removal. It is expected that pipeline tests in FY 2001 will determine the suitability of this approach.

The formulations of the three viscosity samples, which are labeled B1, B2, and B3, were selected to further demonstrate the importance of fluoride concentration. The only difference in the chemical composition for B1, B2, and B3 was the fluoride concentrations, which were $0.15,0.10$, and $0.05 \mathrm{M}$, respectively. It should be noted that the phosphate concentration in these samples was $0.5 \mathrm{M}$. With one exception, the viscosity of the B3 sample was always higher than its B1 and B2 counterparts. In fact, the only sample to form high-viscosity solids was B3. With high concentrations of aluminate, hydroxide, phosphate, silicate, and sulfate, the potential for a pipeline plug increases if the ratio of phosphate concentration to fluoride concentration is more than 5 to 1 . The initial viscosity tests during FY 2001 will more closely determine the phosphate-to-fluoride ratios that can lead to plugs. While the addition of fluoride to the tanks cannot be recommended due to downstream processing concerns, the phosphate. and fluoride concentrations should be key considerations in blending operations. 
In addition to the fluoride and phosphate concentrations, the initial ionic strength of the samples plays a key role in the formation of pipeline plugs. The viscosity results for samples $\mathrm{S} 4$ and S7 from FY 1999 (Hunt et al., 1999) were further evaluated. The fluoride and phosphate concentrations in samples S4 and S7, and in samples $\mathrm{A} 1$ and $\mathrm{A} 8$ from this report, were 0.2 and $0.5 \mathrm{M}$, respectively. The concentrations of the other components in the four samples varied significantly. The combined concentrations of aluminate, hydroxide, and nitrate in samples $\mathrm{S} 7$ and A1 were 3 and $9 M$, respectively, and the samples did not form high-viscosity solids. In sharp contrast, samples $\mathrm{S} 4$ and $\mathrm{A} 8$, with combined concentrations of aluminate, hydroxide, and nitrate of 8.1 and $5.0 \mathrm{M}$, respectively, did produce high-viscosity solids. This observation could have a direct impact on the performance of waste dilution with water to prevent pipeline plugs. A water dilution will reduce the phosphate concentration, which would lower the risk of a pipeline plug. However, a water dilution will also lower the ionic strength of the waste, which may increase or decrease the likelihood of a plug. Therefore, the net effect of a lower phosphate concentration and a lower ionic strength should be considered prior to a waste dilution with water. It is also important to note that the range of suitable ionic strengths for safe waste transfers is influenced by the phosphate concentration and the ratio of phosphate concentration to fluoride concentration. For example, sample B7 formed some high-viscosity solids even though the concentration of phosphate and the combined concentrations of aluminate, hydroxide, and nitrate were 0.2 and $10 \mathrm{M}$, respectively. Apparently, the lack of fluoride in sample B7 could more than compensate for the relatively low phosphate concentration and the high ionic strength.

During FY 2000, six additional samples, which were labeled A4, A5, A6, A7, A9, and A10, were prepared to test the effects of the initial ionic strength. The aluminate, fluoride, and phosphate concentrations in the six samples were $1.0,0.2$, and $0.5 \mathrm{M}$, respectively. The silicate and sulfate concentrations were also held constant, while the concentrations of $\mathrm{OH}^{-}$and $\mathrm{NO}_{3}{ }^{-}$were varied from 1 to $3 \mathrm{M}$. The viscosities of these six samples remained below $4 \mathrm{cP}$ throughout the tests. A comparison of samples A4 and A8 is quite interesting. The only chemical differences between the two samples involve the hydroxide and nitrate concentrations. Sample A 4 contained $2 M$ hydroxide and $2 M$ nitrate, while the hydroxide and nitrate concentrations in sample $\mathrm{A} 8$ were $1 M$ and $3 M$, respectively. After the two samples were cooled from $50^{\circ} \mathrm{C}$ to $18^{\circ} \mathrm{C}$, the viscosities of samples $\mathrm{A} 4$ and $\mathrm{A} 8$ were 2.3 and $24 \mathrm{cP}$, respectively. Therefore, it would appear that the nitrate concentration is a more important factor than the hydroxide concentration in the formation of pipeline plugs. 
However, a comparison of samples $\mathrm{C} 2$ and $\mathrm{C} 3$ would suggest that hydroxide concentration, not nitrate concentration, would be a more critical factor in pipeline plugs. While the individual concentrations of hydroxide and nitrate are not significant factors, the hydroxide and nitrate concentrations are key contributors to the initial ionic strength. It is important to remember that the samples with $0.5 \mathrm{M}$ trisodium phosphate and $0.2 \mathrm{M}$ sodium fluoride would form plugs only at certain initial ionic strengths.

The effect of carbonate was tested in samples $\mathrm{C} 1$ through $\mathrm{C} 7$. For the simulated pump failure from $50^{\circ} \mathrm{C}$ to $18^{\circ} \mathrm{C}$, high-viscosity solids were produced only from the samples with a high phosphate concentration. While these samples indicate that carbonate is not a significant factor in the formation of the plugs, carbonate may play an important role in the stability of the plugs. Nearly all of the high-viscosity solids were stable during gradual cooling over a small temperature range, which did not exceed $15^{\circ} \mathrm{C}$. Sample $\mathrm{C} 3$ was the exception: its high-viscosity solids were stable from 50 to $20^{\circ} \mathrm{C}$. Sample $\mathrm{C} 3$ contained only high concentrations of carbonate, fluoride, and hydroxide, while sample S2 from the FY 1999 study (Hunt et al., 1999) had high concentrations of fluoride, hydroxide, silicon, and sulfate. The stability of the high-viscosity solids for sample S2 was less than $10^{\circ} \mathrm{C}$. Since the impact of silicon and sulfate on the viscosity appears to be very limited, the difference in thermal stability is probably due to the presence of carbonate in combination with the hydroxide. Tests on the simulant formulation for the university contest, which will be described later in detail, also indicate that carbonate can improve the stability of a plug.

\section{MODELING OF THE VISCOSITY RESULTS}

\subsection{PRELIMINARY CONSIDERATIONS}

Building a quantitative model based on the viscosity results in Table 3 is desirable. Furthermore, the model should be easy to use, reliable, and available for the planning of transfers, dilutions, and other waste-processing steps. High-viscosity solids were only observed in a few of the samples over a narrow temperature range. The transitions from low to high viscosity are not gradual or even continuous. Therefore, typical modeling techniques based upon polynomials or smooth functions are not likely to be successful. In fact, several statistical regressions were attempted using traditional smooth functions, but this effort was totally unsuccessful. 
For the most part, the samples can be divided into two discrete groups. The viscosity of the samples in the larger group remained below $10 \mathrm{cP}$ at all temperatures, while the maximum viscosity of the samples in the smaller group normally exceeded $50 \mathrm{cP}$. The RPP has included viscosity in its set of criteria that must be met before a waste can be transferred. Since the maximum allowable viscosity for the RPP is between 10 and $50 \mathrm{cP}$, the ability to distinguish between degrees of highness or lowness is not needed for the model. All samples with consistently low viscosities can be viewed as nonthreatening, and all samples that can produce high-viscosity solids present approximately the same degree of risk.

A second problem in the development of a reliable model involves the lack of specific mechanistic information on the formation of pipeline plugs. The formation of high-viscosity solids is certainly related to buildup of surface charges on particles, particle habit, ionic strength, and water activity. Processes of gelation and coagulation are extremely sensitive to these effects. The Hanford wastes are very complex due to the wide variety of ions, and the precise concentrations of these ions are not known. Therefore, the mechanisms that produce high-viscosity solids cannot be modeled with sufficient reliability. As a result, this study focused on an empirical approach rather than a mechanistic one.

The objective of this modeling effort is to predict the conditions of high viscosity as reliably as possible. However, since no model is perfect, it is preferable that the predictions err on the side of caution. The model should not predict a low viscosity if such a condition will not actually be observed. This false negative might well lead to additional plugged lines. However, it is occasionally acceptable to have a prediction of high viscosity when the experimental results suggest a low viscosity. This false positive may occur in a chemical system that has conditions close to those for high-viscosity solids. Several examples in Sect. 4.2 illustrate this sensitivity to minor adjustments in component inventories. In this sense, a false positive might serve as a warning, which would be more useful than a true prediction of low viscosity.

\subsection{NEURAL NETWORK MODEL}

Over the past few decades, artificial neural networks (ANNs) have become increasingly popular as modeling tools in the chemical and engineering sciences. A neural network is completely empirical and does not require any prespecified functional form, such as a polynomial. An ANN can 
be used as a universal function approximator; that is, a single ANN can approximate any continuous function regardless of its functional form. A special kind of ANN, which is called a classifier, was selected for this effort. A classifier can predict whether a system belongs to a particular set or class. For the Hanford tank farm, the classifier will determine if the viscosity of the proposed waste transfer will be high or low.

Briefly, an ANN consists of input, output, and internal variables, as shown in Fig. 1. The inputs and outputs serve as independent and dependent variables, respectively, of an empirical function. In this model, the inputs are the ion concentrations and the temperature. The only output of the model is viscosity. Each input passes a signal in the form of a numerical value to an internal variable, which is called a hidden node, through some predefined functional form. Using the available input data, each hidden node then passes a signal to the output through a defined functional form. The signals from all of the hidden nodes are combined at the output node to produce the

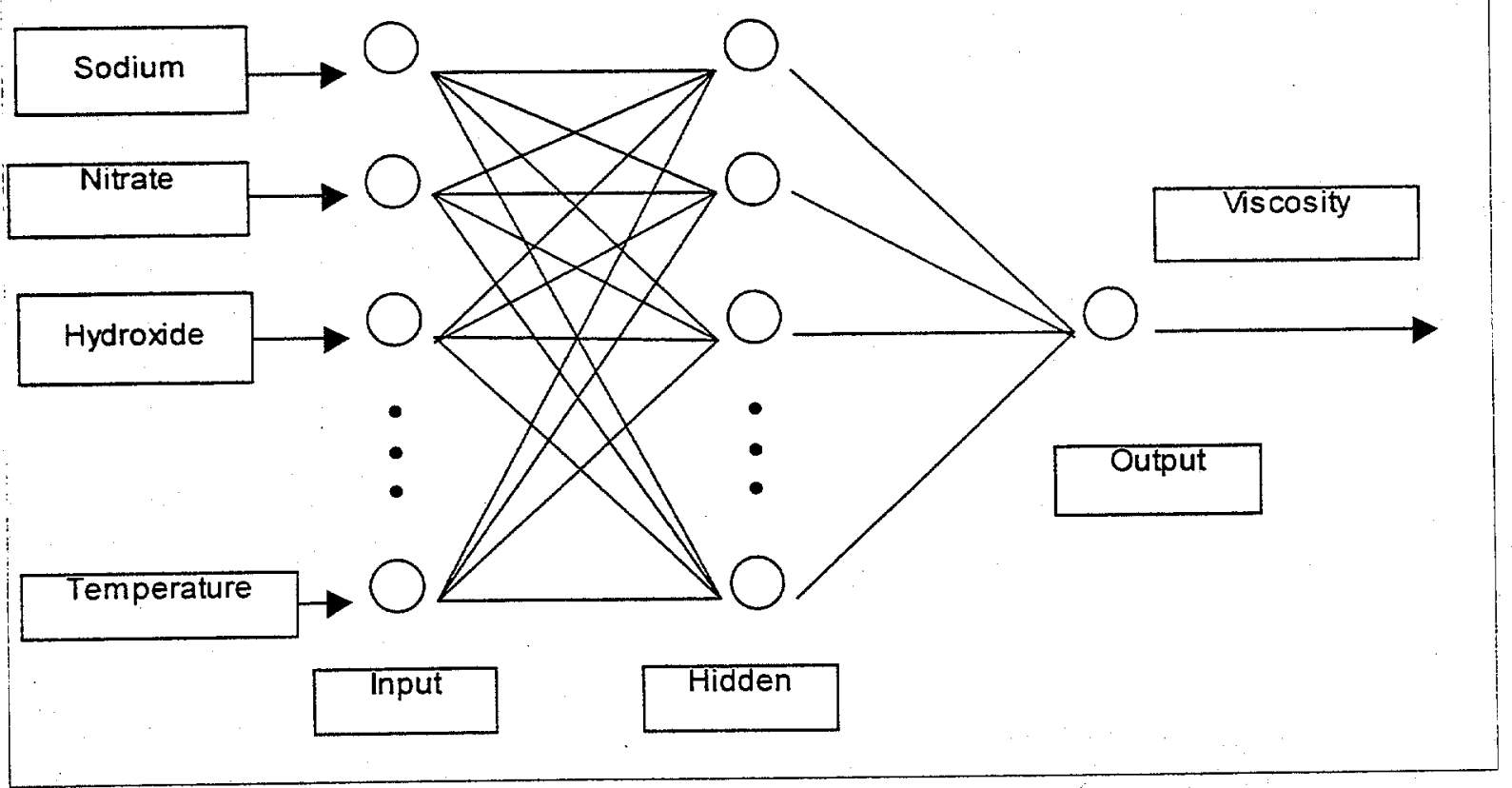

Fig. 1. Input variables, output variables, and internal variables for the classifier. 
output signal. Each function that governs signal passing has certain parameters that must be chosen as part of the model development. The optimal selection of these parameters using actual data constitutes "training" the model. It is common practice not to use all of the available data for training so that the remainder can be used in model validation. Of course, the model developers are concerned with the hidden nodes, the signal-passing functions, and the parameters to be optimized. However, most users need be concerned only with the inputs and outputs, and they can treat the internal workings of the model as a black box.

A classifier neural network was built using the viscosity results in Table 3. After initial classification of the viscosity results, the high- and low-viscosity samples were given the values 1 and 0 , respectively. The model was then trained on randomly selected subsets of the high- and lowviscosity results and tested on other random subsets. Each of these training runs was then ranked based on its ability to successfully predict high-and low-viscosity classes.

Illustrated in Fig. 2 is the median error of these trials on the test data (i.e., $50 \%$ of the training runs produced better predictions, and $50 \%$ produced worse). The test error is a measure of the applicability of the model to new data. The observed class membership (vertical axis) is exactly 0 or 1 , since this variable was assigned based on experimental results. The predicted class membership (horizontal axis) is a number between 0 and 1 on a continuous scale. If the model is working very well, all points will be clustered in the vicinity of $(0,0)$ and $(1,1)$. If the model is working adequately, then the predicted values for low-viscosity points will be less than 0.5 while the high-viscosity points would be greater than 0.5 . As seen in Fig. 1, this median case satisfies nearly all of these criteria. All of the high-viscosity points are predicted to be high viscosity. Most of the low-viscosity points are clustered near $(0,0)$, so the model predicts them to be low. However, the model exhibits one false positive at $(0.7,0)$ and one inconclusive prediction at $(0.5,0)$. In both cases, the experimental results indicated low viscosity at these points. The two points correspond to the data entries in Table 7.

While samples A3 and B4 produced high-viscosity solids, these solids were not detected at the temperatures designated by the ANN. Therefore, the classifier correctly predicted problems based on chemical composition but was incorrect regarding temperature.

While the current model is preliminary, it has successfully demonstrated the applicability of an ANN in waste evaluation. Improvements and extensions are part of the ongoing model development. More advanced model training techniques will lead to higher success rates in 


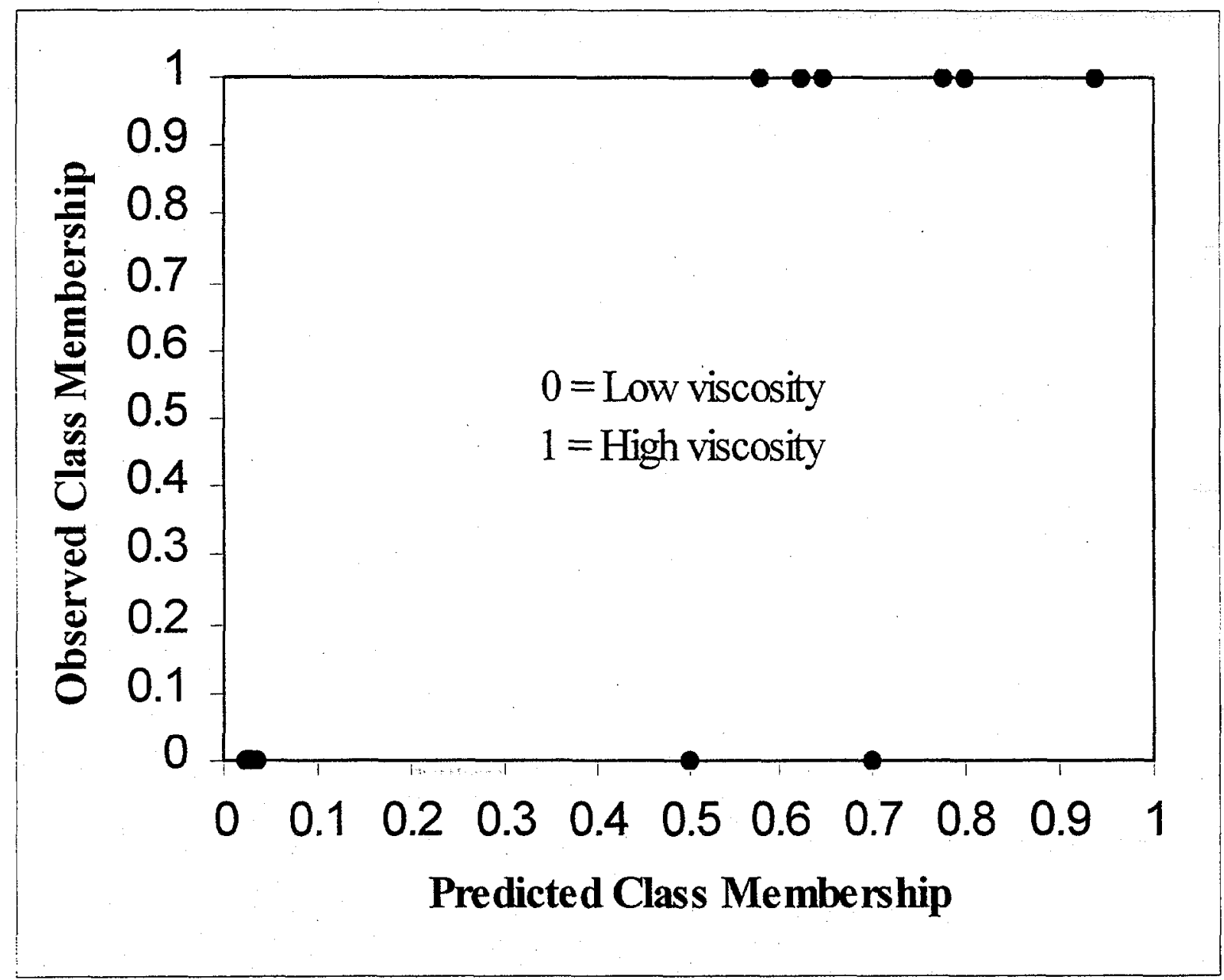

Fig. 2. Median result of the classifier's predictions of high and low viscosities.

prediction and generalization. In addition, the model predictions will improve as more experimental results are added to the data base. One of the greatest limitations in the current analysis is the relatively small number of high-viscosity points. Additional input variables and hidden nodes can be easily added to the classifier. Current plans are to include other input variables such as the carbonate concentration and the effects of rapid temperature drops, as shown in Table 6. Finally, the model predictions will be used to guide future viscosity experiments so the areas of high uncertainty can be reduced further. 
Table 7. Formulations and concentrations of the AN-103, AZ-101, and C-104 simulants

\begin{tabular}{|c|c|c|c|c|c|c|}
\hline Compound & $\begin{array}{c}\text { Grams } \\
(\mathrm{AN}-103)\end{array}$ & $\begin{array}{c}\text { Moles/ } \\
\text { molality } \\
(\mathrm{AN}-103)\end{array}$ & $\begin{array}{c}\text { Grams } \\
(A Z-101)\end{array}$ & $\begin{array}{c}\text { Moles/ } \\
\text { molality } \\
(\mathrm{AZ}-101) \\
\end{array}$ & $\begin{array}{l}\text { Grams } \\
(\mathrm{C}-104) \\
\end{array}$ & $\begin{array}{l}\text { Moles/ } \\
\text { molality } \\
(\mathrm{C}-104)\end{array}$ \\
\hline $\mathrm{NaAlO}_{2}$ & 162.49 & 1.982 & 9.68 & 0.118 & 367.73 & 4.486 \\
\hline $\mathrm{Al}\left(\mathrm{NO}_{3}\right)_{3} \cdot 9 \mathrm{H}_{2} \mathrm{O}$ & 413.82 & 1.103 & 113.54 & 0.303 & 0.00 & 0.000 \\
\hline $\mathrm{NaCl}$ & 8.62 & 0.148 & 0.00 & 0.000 & 0.00 & 0.000 \\
\hline $\mathrm{Na}_{2} \mathrm{CO}_{3}$ & 73.30 & 0.692 & 44.19 & 0.417 & 115.21 & 1.087 \\
\hline $\mathrm{NaF}$ & 2.55 & 0.061 & 3.12 & 0.074 & 0.00 & 0.000 \\
\hline $\mathrm{Fe}\left(\mathrm{NO}_{3}\right)_{3} \cdot 9 \mathrm{H}_{2} \mathrm{O}$ & 0.00 & 0.000 & 0.00 & 0.000 & 153.80 & 0.381 \\
\hline $\mathrm{Fe}_{2} \mathrm{O}_{3}$ & 0.00 & 0.000 & 0.00 & 0.000 & 22.78 & 0.143 \\
\hline $\mathrm{Mn}\left(\mathrm{NO}_{3}\right)_{2}$ & 0.00 & 0.000 & 0.00 & 0.000 & 30.78 & 0.172 \\
\hline $\mathrm{NaNO}_{3}$ & 170.16 & 2.002 & 89.92 & 1.058 & 0.00 & 0.000 \\
\hline $\mathrm{NaOH}$ & 269.75 & 6.744 & 49.36 & 1.777 & 81.52 & 2.038 \\
\hline $\mathrm{Na}_{2} \mathrm{C}_{2} \mathrm{O}_{4}$ & 0.00 & 0.000 & 0.00 & 0.000 & 28.94 & 0.216 \\
\hline $\mathrm{Na}_{3} \mathrm{PO}_{4} \cdot 12 \mathrm{H}_{2} \mathrm{O} \cdot 1 / 4 \mathrm{NaOH}$ & 12.18 & 0.031 & 4.52 & 0.012 & 28.48 & 0.073 \\
\hline $\mathrm{Na}_{2} \mathrm{SiO}_{3} \cdot 5 \mathrm{H}_{2} \mathrm{O}$ & 6.04 & 0.028 & 2.40 & 0.011 & 103.95 & 0.490 \\
\hline $\mathrm{Na}_{2} \mathrm{SO}_{4}$ & 6.40 & 0.045 & 20.01 & 0.141 & 8.95 & 0.063 \\
\hline $\mathrm{ZrF}_{4}$ & 0.00 & 0.000 & 0.00 & 0.000 & 102.17 & 0.611 \\
\hline $\mathrm{ZrO}_{2}$ & 0.00 & 0.000 & 0.00 & 0.000 & 42.51 & 0.345 \\
\hline $\mathrm{H}_{2} \mathrm{O}$ & 884.78 & 49.113 & 952.27 & 52.859 & 1086.60 & 60.316 \\
\hline
\end{tabular}

\subsection{APPLICATIONS TO WASTE PROCESSING}

This preliminary evaluation clearly illustrates the potential usefulness of the classifier to identify conditions that can lead to a plugged pipeline. With the exception of the model developers, this model can be treated as an empirical black box. The model is easy to use since the input requirements are waste composition and temperature. If the input values are not known, then several representative values can be tried so the entire range of uncertainty can be covered. The output on the potential for high viscosity is nearly instantaneous; therefore, parametric studies of input values can be done quickly. 
Because this classifier is a not a mechanistic model, it does not require a wide variety of input parameters. This model does not predict the species present in the samples or the wastes, but it can use the results of thermodynamic equilibrium models such as the Environmental Simulation Program (ESP). It is important to remember that the formation of pipeline plugs is closely related to viscosity, which is a nonequilibrium quantity. Unfortunately, the effects of temperature on the viscosities of the Hanford wastes cannot be easily obtained. Therefore, this classifier and the viscosity results will help to fill this information void in a way that can be easily used in the development and implementation of waste-processing strategies.

\section{SIMULANT FORMULATIONS FOR HANFORD}

\subsection{SIMULATED HIGH-NITRATE PLUG FOR THE UNIVERSITY CONTEST}

A pipeline plug occurred during the transfer of supernatant from Hanford tank SX-104. In response to this plug, a grab sample of supernatant was obtained, characterized, and modeled (Herting, 1998). When the supernatant was permitted to cool to $22^{\circ} \mathrm{C}$, an extensive network of solids, which could easily lead to a pipeline plug, was observed. The key crystals in the network were trisodium phosphate and sodium nitrate. The supernatant sample contained $2.37 \times 10^{4} \mu \mathrm{g} / \mathrm{mL}$ of aluminum, $7.39 \times 10^{3} \mu \mathrm{g} / \mathrm{mL}$ of chloride, $2.54 \times 10^{5} \mu \mathrm{g} / \mathrm{mL}$ of nitrate, $1.02 \times 10^{5} \mu \mathrm{g} / \mathrm{mL}$ of nitrite, $4.84 \times 10^{3} \mu \mathrm{g} / \mathrm{mL}$ of phosphate, $2.43 \times 10^{3} \mu \mathrm{g} / \mathrm{mL}$ of potassium, $2.22 \times 10^{5} \mu \mathrm{g} / \mathrm{mL}$ of sodium, and $9.27 \times 10^{3} \mu \mathrm{g} / \mathrm{mL}$ of sulfate. The RRP has used these analytical results in an attempt to model the chemical system with the ESP. For the initial input into the ESP, the RPP selected the following chemical compounds and concentrations: $0.064 \mathrm{M}$ potassium chloride, $0.96 \mathrm{M}$ sodium aluminate, $0.379 \mathrm{M}$ sodium carbonate, $0.126 \mathrm{M}$ sodium chloride, $1.41 \mathrm{M}$ sodium hydroxide, $4.69 \mathrm{M}$ sodium nitrate, $2.18 \mathrm{M}$ sodium nitrite, $0.143 \mathrm{M}$ trisodium phosphate, and $0.066 \mathrm{M}$ sodium sulfate. The addition of sodium carbonate to the input data was quite reasonable based on an analysis of the best-basis inventory for Hanford tank SX-104.

The Retrieval Program of the TFA has requested a chemical simulant of the SX-104 plug for use in a university contest on potential recovery methods. The RPP findings were used to prepare the first chemical simulant of the SX-104 plug. The initial simulant contained $1 M$ sodium aluminate, $0.4 M$ sodium carbonate, $1.5 M$ sodium hydroxide, $7 M$ sodium nitrate, and 
$0.2 M$ trisodium phosphate. Several modifications to the initial formulation were evaluated. The addition of sodium fluoride and increases in the concentrations of carbonate, nitrate, and phosphate assisted in the formation of simulated pipeline plugs. In contrast, the addition of the sodium silicate and increases in the concentration of hydroxide did not improve the simulated plug. These observations were used to develop the plug that was used in the university contest. The simulated plug for the contest contained $2 M$ sodium aluminate, $0.6 M$ sodium carbonate, $0.3 \mathrm{M}$ sodium fluoride, $2 M$ sodium hydroxide, $8 M$ sodium nitrate, and $0.9 M$ trisodium phosphate. The aluminate, phosphate, carbonate, and fluoride concentrations for the contest were considerably higher than the corresponding values for the actual liquid waste from tank SX-104. Higher concentrations were needed to form an adequate plug in a new pipe in only a few hours, as well as to maintain the stability of the plug as its temperature was increased to $50^{\circ} \mathrm{C}$, the maximum permitted in the contest.

\subsection{SIMULANTS FOR THE TRANSFER TESTS AT AEA, FIU, AND MSU}

TFA and the RPP requested that research staff members at AEA Technology, FIU, and MSU study the waste transfers during saltwell pumping and retrieval operations. The waste in the saltwell pumping will initially contain high salts and no solids, and the flow rate will be between 0.5 and $3 \mathrm{gal} / \mathrm{min}$. In contrast, the waste in the retrieval operations can contain a maximum of $20 \mathrm{wt} \%$ solids, and the flow of the waste should remain turbulent during the transfer. The researchers at FIU focused on the waste in Hanford tanks AN-103 and AZ-101, which will be retrieved by the RPP in the near future. The staff members at MSU examined the saltcake liquid from Hanford tanks SX-104 and U-103, which led to plugged pipelines during saltwell pumping. In order to support the activities at the university, AEA Technologies examined the key precipitation properties of the waste in tanks AN-103 and SX-104 (Francis et al., 2000).

The test conditions, such as flow rates and temperature ranges, were provided by personnel at Oak Ridge and Hanford. The best-basis inventories in the Tank Waste Information Network System were used to develop simulants of tanks AN-103, AZ-101, SX-104, and U-103, while the development of the SX-104 simulant was described earlier. For tank AN-103, the retrieval of the waste will be conducted in two stages. The supernatant in tank AN-103 will be transferred to tank AN-103 with a moderate amount of dilution water, if needed, to ensure transportability. The remaining solids will then be dissolved or slurried with 500,000 gal of water and delivered directly 
to the plant for pretreatment and vitrification. This effort was focused on the second transfer of waste. For tank AZ-101, the entire contents will be slurried with no additional water and transported to the pretreatment and vitrification facility. For the simulants of wastes in tanks AN-103 and AZ-101, the primary objectives were to closely mimic the chemical composition of the selected waste and to minimize the probability of potentially hazardous reactions, such as the formation of poisonous nitrogen oxide. The chemical components in the AN-103 and AZ-101 simulants are listed in Table 7. In addition, the percentages of solids in the simulants of tanks AN-103 and AZ-101 were required to be below the limits that were set by the RPP. Small samples of the AN-103 and AZ-101 simulants were prepared, and the volume percent of solids was determined. The AN-103 and AZ-101 simulants contained 10 and 5\% solids, respectively. Calculations using the ESP were performed by MSU researchers to confirm the suitability of the simulants. This evaluation indicated that the AZ-101 simulant without iron would not present a sufficient challenge. Therefore, the RPP recommended that tank $\mathrm{AZ}-101$ be replaced with tank C-104.

Because the waste in tank C-104 is classified as a sludge, a waste transfer without dilution water may exceed the RPP limits on the percent solids or viscosity. In order to determine the need for dilution water, the initial formulation of the tank C-104 simulant was developed based on the best-basis inventory prior to any water additions. The settled solids in the initial formulation were $20 \%$ of the total volume, and they appeared to be loosely packed. Two layers of liquids were observed above the settled solids. The liquid layer, which was directly above the solids, was dark red in color, probably because of the ferric oxide. This liquid layer produced a film of fine particles on the wall of the sample bottle. A colorless liquid layer was observed above the red liquid layer. With the initial formulation, the ESP predicted that the solids content in the tank C-104 simulant would only be $15 \mathrm{wt} \%$. The experimental and theoretical results indicated that dilution water would not be needed to meet the RPP criteria of percent solids. At first, this result may appear surprising for a waste that is classified as a sludge. However, the RPP has experimentally determined that the water content in tank C-104 sludge is between 40 and $60 \%$ and that the water content in the tank C-104 simulant is 50\%.

A series of viscosity tests on the initial formulation of tank $\mathrm{C}-104$ waste was performed. The viscosity of the original $\mathrm{C}-104$ simulant at $50^{\circ} \mathrm{C}$ was $19 \mathrm{cP}$ at a shear rate of $36.7 \mathrm{~s}^{-1}$. Therefore, the viscosity of the simulant is slightly below the waste transfer criteria. When the sample was cooled to 45 and $40^{\circ} \mathrm{C}$, the viscosity of the tank C- 104 simulant increased dramatically to $4400 \mathrm{cP}$ at a shear 
rate of $0.12 \mathrm{~s}^{-1}$. The high viscosity measurement could be due to small particles that were firmly attached to the stainless steel and plastic surfaces in the rheometer. The viscosity measurements at 45 and $40^{\circ} \mathrm{C}$ clearly indicated that the original formulation of tank C- 104 simulant was not suitable for the waste transfer tests at FIU. Because the RPP is considering the addition of water to tank $\mathrm{C}-104$, the effect of water dilution on the tank C-104 simulant was measured. Water was added to the tank C-104 simulant as a function of weight percent of the original C-104 sample. The diluted sample was permitted to equilibrate for several days before its viscosity was measured. The effects of water dilution on the viscosity of the $\mathrm{C}-1.04$ simulant are shown in Table 8. The results indicate that the waste in tank $\mathrm{C}-104$ should be diluted by a minimum of $75 \%$. At $100 \%$ dilution, the maximum viscosity should be approximately $11 \mathrm{cP}$, and the volume of solids in the diluted waste should be less than $10 \%$. The dilution requirements for tank $\mathrm{C}-104$ will be confirmed in transfer tests at FIU.

Table 8. Effects of water dilution on the viscosity of the tank C-104 simulant

\begin{tabular}{cccc}
\hline $\begin{array}{c}\text { Temperature } \\
\left({ }^{\circ} \mathrm{C}\right)\end{array}$ & $\begin{array}{c}\text { Dilution water } \\
\text { (wt \% of initial sample) }\end{array}$ & $\begin{array}{c}\text { Viscosity } \\
(\mathrm{cP})\end{array}$ & $\begin{array}{c}\text { Shear rate } \\
\left(\mathrm{s}^{-1}\right)\end{array}$ \\
\hline 50 & 0 & 19 & 37 \\
45 & 0 & 4400 & 0.1 \\
40 & 0 & 4400 & 0.1 \\
40 & 25 & 3300 & 0.1 \\
40 & 50 & 420 & 1 \\
40 & 75 & 13 & 55 \\
15 & 75 & 17 & 43 \\
15 & 100 & 11 & 61 \\
\hline
\end{tabular}

While the potential for pipeline plugs during the proposed retrieval transfers was not known at the time the simulants were formulated, the transfers of liquid in tanks SX-104 and U-103 have led to plugged pipelines. Therefore, suitable simulants of tanks SX-104 and U-103 should form high-viscosity solids after they are permitted to cool to ambient conditions. Three simulants of the SX-104 waste were prepared based on the analytical results provided by the RPP, and the simulant 
samples were tested extensively in the Brookfield rheometer. The compositions of two of these simulants, which were labeled B7 and B11, are reported in Table 2. The composition of the third simulant was based on the composition of the B7 sample, with the addition of $0.4 \mathrm{M}$ sodium carbonate. While the three formulations are very similar, their abilities to form a pipeline plug were considerably different. The viscosity of the B11 sample always remained low. An intermediate viscosity of $31 \mathrm{cP}$ was observed after the $\mathrm{B} 7$ sample was cooled from $50^{\circ} \mathrm{C}$ to room temperature during a simulated pump failure. In sharp contrast, the viscosity of the B7 sample to which sodium carbonate was added exceeded $6000 \mathrm{cP}$ during the simulated pump failure at $50^{\circ} \mathrm{C}$. The requirement that a plug be formed as the simulant is cooled led to the recommendation of the $\mathrm{B} 7+$ $0.4 M$ sodium carbonate formulation as the SX-104 simulant for AEA Technologies and MSU. It is important to remember that the flow conditions of the tests at AEA Technologies, MSU, and ORNL were considerably different. Therefore, the other sites were permitted to make small modifications in the formulation so that their simulants could more closely mimic the conditions that led to the actual pipeline plug at Hanford (Welch et al., 2000).

The initial formulation of the simulant for tank U-103 was based on the liquid associated with the saltcake in the best-basis inventory. This formulation did not form high-viscosity solids as it was cooled from $30^{\circ} \mathrm{C}$ to room temperature. Viscosity results at 30 and $20^{\circ} \mathrm{C}$, which are shown in Table 9, confirmed that the initial formulation could not adequately simulate the pipeline plug, because of filtered liquid from tank U-103. The presence of a considerable amount of solids in the simulant of a liquid was also a concern. Therefore, a modification to the formulation was required. This modified formulation contained 1.2 M sodium aluminate, $1.5 \mathrm{M}$ sodium hydroxide, and 6.2 M sodium nitrate. The only variable in this new formulation was the phosphate concentration, which is $0.04 \mathrm{M}$ in the best-basis inventory. The concentration of trisodium phosphate was increased from $0.04 \mathrm{M}$ to $0.10 \mathrm{M}$ in increments of $0.02 \mathrm{M}$ in an effort to improve the probability of a plug formation. The viscosity results clearly show that small increases in the phosphate concentrations can lead to dramatic increases in the viscosity of the samples. The modified formulation with a phosphate concentration between 0.06 and $0.08 \mathrm{M}$ was provided to MSU for its initial tests on tank U-103, even though the simulant contained solids at $30^{\circ} \mathrm{C}$. 
Table 9. Simulants of tank U-103: initial volume of gravity-settled solids and final viscosity

\begin{tabular}{|c|c|c|c|c|}
\hline Sample ID & $\begin{array}{l}\text { Viscosity }(\mathrm{cP}) \text { : } \\
30^{\circ} \mathrm{C}\end{array}$ & $\begin{array}{l}\text { Volume percent } \\
\text { of solids: } 30^{\circ} \mathrm{C}\end{array}$ & Types of solids: $30^{\circ} \mathrm{C}$ & $\begin{array}{c}\text { Viscosity (cP): } \\
20^{\circ} \mathrm{C} \\
\end{array}$ \\
\hline Best basis inventory & 3.6 & 15 & Fine powder & 4.2 \\
\hline Modified formula $+0.10 \mathrm{MPO}_{4}$ & $>6000^{\circ}$ & 20 & $\begin{array}{l}\text { Fine powder, large crystals, } \\
\text { and long needle crystals }\end{array}$ & $>6000^{a}$ \\
\hline Modified formula $+0.08 \mathrm{MPO}_{4}$ & 6.8 & 10 & Fine powder & $>6000^{a}$ \\
\hline Modified formula $+0.06 \mathrm{MPO}_{4}$ & 6.6 & 15 & Fine powder and large crystals & $455^{b}$ \\
\hline Modified formula $+0.04 \mathrm{MPO}_{4}$ & 5.1 & 10 & Fine powder & 7.2 \\
\hline
\end{tabular}

Previously, the RPP has stated its concern about the uncertainties in the best-basis inventory and in analytical results. This study of the tank U-103 simulants clearly demonstrates that the uncertainties in the best-basis inventory can lead to erroneous assumptions about the potential for plug formation. Potential problems due to uncertainties in the analytical results can be easily seen in the chemical analysis of an actual liquid sample from tank U-103 (Herting, 1999). The phosphate concentration was more than 2.4 times greater with the inductively coupled plasma spectroscopy than with the ion chromatography. Our study has demonstrated that a much smaller difference in phosphate concentration can lead to pipeline plugs.

\section{RESULTS FROM THE UNIVERSITY CONTEST ON PLUG REMOVAL}

The most-promising processes from the university contest on plug removal will be evaluated for potential application in the Hanford tank farm. During FY 2001, suitable processes will be tested in a small test apparatus at ORNL. Quantitative analysis will be used to determine if any of these processes will be evaluated in the pilot-scale pipeline system at FIU.

\subsection{TENTH ANNUAL ENVIRONMENTAL DESIGN CONTEST}

The Waste-Management Educational and Research Consortium (WERC) - which comprises Diné College, Los Alamos National Laboratory, New Mexico Institute of Mining and 
Technology, New Mexico State University, the University of New Mexico, and Sandia National Laboratory - held its tenth annual environmental design contest in April 2000. One of the eight research problems for the design contest was the development and demonstration of a method to remove a phosphate-nitrate plug from a pipeline. No proposed solution could damage the pipe, produce any dangerous by-products, or increase the health hazards to the tank farm operators. Both chemical and physical processes were permitted. Due to operational and safety considerations, the temperature and pressure could not exceed $50^{\circ} \mathrm{C}$ and $50 \mathrm{psi}$, respectively. In addition, strong oxidizers, acids with $\mathrm{p} K$ values of less than 4.0 , and mechanical intrusion were not permitted. Even with these design constraints, five universities were able to develop methods to remove the phosphate-nitrate plug. The selection processes, which were used by the universities to determine the best removal methods, are described below.

\subsection{MICHIGAN TECHNOLOGICAL UNIVERSITY}

A management system for the removal of a phosphate-nitrate plug in a cross-site hazardous waste transfer line was designed based on effectiveness, environmental impact, and cost. Six physical and chemical methods were assessed. These options included ultrasound, air and water pressure, vibrations, oscillating flow, a crown ether, and acetic acid. The chosen solution, which was based on laboratory tests and an engineering analysis, suggested that chemical methods were superior. The use of a crown ether and a portable truck/reserve system was designed to implement this procedure. The portable system can be transported to the necessary access pipes. The crown ether will be pumped into the pipeline via the access pipe, which will be connected to a reservoir system. The crown ether will then react with the sodium in the plug to permit the flow of liquid through the pipeline.

The design for this solution involves no extra building costs other than the truck/reservoir system. An effort was made to use existing personnel and facilities to reduce cost. The time needed to effectively remove the chemical precipitation is dependent on the size of the plug. It is estimated that 96 days and $\$ 610,000$ would be needed to remove a 100 -m-long plug. 


\subsection{MONTANA TECH}

The Montana Tech Environmental Design Team (MTEDT) evaluated six different technologies to restore flow through a plugged pipeline. These technologies included acid treatment after the displacement of sodium hydroxide, electrolysis, use of ultrasonic waves, hydrojetting, freezing the solids, and a double-action piston with a hot water flush and a carbon dioxide injection. The MTEDT found that the combination mechanical-chemical process was the best method of removing the pipeline plug. Mechanical action of the blockage is achieved using a double-action pneumatic piston. Hot water is injected into the pipeline, and the alternating pressure wave motion and the hot water soften the blockage. Carbon dioxide is also injected into the pipeline to lower the $\mathrm{pH}$ of the caustic solution and to further soften the blockage. A final hot water flush is performed at $35 \mathrm{psig}$ and $45^{\circ} \mathrm{C}$. This combination mechanical-chemical method completely removes the blockage. The total first-year costs are expected to be approximately $\$ 250,000$ for labor, overhead, materials, and equipment. The approximate time cycle for the removal of one plug is estimated at 4 weeks.

\subsection{OHIO UNIVERSITY}

The Ohio University Plug Removal Design Team (OUPRDT) considered many possible methods such as use of enzymes, strong acids, acoustic cavitation, and a water hammer to unplug the radioactive waste pipelines. Due to contest limitations, OUPRDT selected the use of an impulse pressure, which is induced onto the fluid in the pipe with a subsonic wave. The equipment for this process included a solenoid piston, hydraulic shaker, mounting equipment, and miscellaneous piping. The solenoid piston introduces an instantaneous force onto the system, which pushes the plug through the pipeline. In combination with the impulse force, the hydraulic shaker will be used to generate waves in the pipe walls to reduce the frictional force between the crystalline plug and the walls. The reduction in the frictional force will facilitate the movement of the plug through the pipeline. In addition, the vibration in the pipe walls can produce a break in the interface between the plug and the wall. The estimated total cost of this effort is $\$ 90,000$, and 11 months will be needed to unplug the preexisting plugged pipelines. 


\subsection{OREGON STATE UNIVERSITY}

Several pipelines that were used to transfer high-level radioactive waste from the underground tanks at several U.S. Department of Energy (DOE) sites can no longer be used due to plugs. The Oregon State University Chemical Engineering Department considered five options for restoring flow through a plugged pipeline and dissipating as much of the plug as feasible. The options included an electrode, an electrochemical method, sound waves, a positively charged membrane, and a mechanical plunger. A combination of the positively charged membrane and the mechanical plunger proved to be the most successful solution. The positively charged membrane with dilute acetic acid was placed into the basic solution for approximately $16 \mathrm{~h}$. After the membrane was removed, a mechanical plunger was placed into the pipe. The plunger generated fluid hammer waves, which gradually destroyed the plug. This method successfully unplugged the benchscale pipe within $24 \mathrm{~h}$.

This method will take an estimated 7 weeks to remove the plugs in the four cross-site lines at Hanford. This procedure can then be used to support DOE through the prevention and removal of future pipeline plugs. The initial total cost is $\$ 17,000$, and the annual cost is $\$ 70,000$ (in FY 2000 dollars). Because of the small amount of waste produced by this procedure, disposal cost was not included in the estimate.

\subsection{PURDUE UNIVERSITY}

The Purdue Environmental and Technological Engineers (PETE) evaluated four processes to restore flow in high-level radioactive waste underground transfer lines. These options included sonochemistry, hydrogen-saturated cationic-exchange beads, the use of carbon dioxide with applied pressure, and the use of other inorganics such as boric, phosphoric, and sulfuric acids. The PETE selected carbon dioxide with applied pressure as the best alternative for the plugged pipeline. The carbon dioxide was continuously injected into the caustic solution above the plug, while a pressure of $20 \mathrm{psi}$ was periodically applied to the plug. The carbon dioxide reacts with water to form carbonic acid. Since carbonic acid is considerably less dense than sodium hydroxide, the initial production of carbonic acid was used primarily to neutralize the caustic solution above the plug. The minimum $\mathrm{pH}$ value that was achieved in the simulated waste solution was 5.7. The significant amounts of 
carbonic acid did not reach the plug for $8 \mathrm{~h}$. Once the carbonic acid reached the plug, the dissolution of the plug was accelerated and flow was restored within $2 \mathrm{~h}$. The removal by mass of the plug was approximately $70 \%$.

The full-scale process was designed for direct transport to the nearest access point in the plugged line. Tanker truckers and a flatbed trucker would be transported to the plugged area. The total project cost was estimated to be $\$ 513,000$, with a total estimated project time of 4 months. To remove each subsequent plug, approximately 5 weeks would be required.

\subsection{RESULTS OF THE UNIVERSITY COMPETITION}

Each university was given approximately $48 \mathrm{~h}$ to remove a phosphate-nitrate plug that had been previously prepared by WERC staff members. While most of the processes that were tested in the FY 1999 contest restored flow within $24 \mathrm{~h}$, all of the FY 2000 methods failed to accomplish this. The FY 1999 simulant was a simple mixture of sodium fluoride, sodium hydroxide, and trisodium phosphate, while the FY 2000 simulant was designed to closely mimic the plug in the transfer line from tank SX-104. The formulations of the FY 1999 and FY 2000 simulants are found in Table 2. At the end of the FY 2000 contest, the size and rigidity of the treated plugs were examined. Based on this analysis, the carbon dioxide processes that were selected by Purdue University and Montana Tech appeared to be the most promising technologies. Representatives from the retrieval and pretreatment programs of the TFA estimated that Purdue University and Montana Tech could have restored partial flow in another $24 \mathrm{~h}$.

As part of this contest, the simulated plugs for FY 1999 and FY 2000 were compared by the TFA representatives and the WERC staff members. This evaluation clearly indicated that the FY 2000 simulant performed considerably better as a plug than the FY 1999 simulant, which was composed of sodium orthophosphate needle-like crystals and gels of natrophosphate. The phosphate concentration, which is a significant factor in the formation of a pipeline plug, was $0.9 \mathrm{M}$ in the FY 1999 simulant and $0.2 \mathrm{M}$ in the FY 2000 simulant. Therefore, the performance of a plug cannot be directly related to the concentration of phosphate. Tests indicated that the improved performance of the FY 2000 plug could be attributed to the lack of fluoride and the use of inert solids such as sodium carbonate. Therefore, the performance of a simulated plug is affected not only by the chemical components and conditions that are needed for the initial formation. It is possible that 
relatively inert solid particles trapped by the orthophosphate needle-like crystals improved the performance.

Another important result from this contest was the observation that the best removal methods utilized a combination of chemical and physical processes. The previous attempts to remove pipeline plugs at Hanford were focused on physical processes, with various degrees of success. Chemical methods could not be adequately developed and tested because necessary information such as the chemical composition of the plugs was not available. Due to an extensive characterization effort by DOE, a considerable amount of data on the chemical composition of the Hanford tank wastes is now available. When the characterization results are combined with our expanding knowledge of tank waste chemistry, the chemical methods to remove plugs become viable options and can improve the performance of the physical processes.

\section{PRECIPITATE FORMATION AND LINE PLUG AT SAVANNAH RIVER}

\subsection{SIMULANT OF THE ALUMINOSILICATE PLUG FOR THE SRS}

Due to the importance of the $242-16 \mathrm{H}$ evaporator, researchers at the SRS conducted a study on the formation of sodalite $-\mathrm{Na}_{8} \mathrm{Al}_{6} \mathrm{Si}_{6} \mathrm{O}_{24}\left(\mathrm{NO}_{3}\right)_{2} \cdot 4 \mathrm{H}_{2} \mathrm{O}$ - at 40,95 , and $110^{\circ} \mathrm{C}$ in tank $43 \mathrm{H}$ simulants with various amounts of aluminum and silicon (Wilmarth et al., 1997b). This study determined that the evaporation of the waste in tank $43 \mathrm{H}$ during the summer of 1997 should form only minor quantities of the aluminosilicate. In addition, the Savannah River results indicated that the nitrated sodium aluminosilicate should form during the 4-h residence time of the liquid in the evaporator. However, the SRS researchers were unable to produce large aluminosilicate particles, which could lead to a plugged GDL. A simulated pipeline plug is needed to test plug removal methods.

The formulations in the Savannah River study (Wilmarth et al., 1997b) were prepared at ORNL. The tank $43 \mathrm{H}$ simulant contained $4.0 \mathrm{M}$ sodium hydroxide, $1.5 \mathrm{M}$ sodium nitrate, and $0.4 \mathrm{M}$ sodium aluminate. After sodium silicate was added to samples of the tank $43 \mathrm{H}$ simulant, the silicon-to-aluminum ratio was $1 / 1,1 / 10$, or $1 / 100$. In 1997 , the silicon-to-aluminum ratio in $\operatorname{tank} 43 \mathrm{H}$ was $1 / 100$. Increases in the concentration of silicon in the tank $43 \mathrm{H}$ simulant did produce more solids as expected. However, no large aluminosilicate particles were observed. Changes in 
temperatures and agitation slightly increased the particle size of most aluminosilicates. However, the large particles would not result in a plugged pipeline. Next, the lids for these samples were removed, and the samples with the tank $43 \mathrm{H}$ simulants were heated to $95^{\circ} \mathrm{C}$ until most of the water had evaporated. The solids in the sample with the silicon-to-aluminum ratio of $1 / 1$ were not altered, and the solids were easily suspended. In the samples with the lower concentrations of silicon, the evaporation produced a gel-like mass that contained large particles. Due to the adhesive nature of the gel-like solids, attempts to resuspend these solids were not successful. The solids were easily broken apart after water was added back to the system. Therefore, no further attempts were made to form a plug based on the tank $43 \mathrm{H}$ simulant.

The preparation of the various simulated waste solutions for the SRS (D. D. Walker, 1999) was evaluated, and a simplified formulation was developed. The key components in the simplified Savannah River simulant were the concentrations of hydroxide, nitrate, and sodium. Chloride, which can easily be incorporated into the aluminosilicates in the form of sodalite, was added to maintain charge balance. The simplified simulant contained $1.2 \mathrm{~m}$ sodium chloride, $2.2 \mathrm{~m}$ sodium hydroxide, and $2.2 \mathrm{~m}$ sodium nitrate. Various amounts of silicic acid and trihydrate aluminum oxide, which is gibbsite, were added to this new simulant. In the preparation of the samples, the simplified simulant was divided into two equal volumes. The gibbsite was added to one of the aliquots, while the silicic acid was added to the other. After the two aliquots were permitted to equilibrate for $24 \mathrm{~h}$, they were combined at ambient temperature. When the gibbsite and silicic acid solutions were combined, two different types of solids were observed. These solids included very fine particles, which were easily suspended, and a gel-like material on top of clear liquid. The largest gel formation occurred in the sample that contained $1 \mathrm{~m}$ silicic acid and $0.2 \mathrm{~m}$ gibbsite, while the greatest number of fine particles was observed in the sample that contained $1 \mathrm{~m}$ silicic acid and $1 \mathrm{~m}$ gibbsite. These two samples were placed in a water-bath shaker, heated to $70^{\circ} \mathrm{C}$, and rotated at $100 \mathrm{rpm}$. For the sample with $0.2 \mathrm{~m}$ gibbsite, this treatment destroyed the gel and produced fine particles. In sharp contrast, the sample with $1 \mathrm{~m}$ gibbsite formed layers of solids that completely plugged the sample container. The procedure to form a pipeline plug with aluminosilicates includes high concentrations of aluminum and silicon, as well as agitation at $70^{\circ} \mathrm{C}$. Details concerning this procedure were provided to SRS personnel for use in their tests on aluminosilicates. 
During an evaluation of the procedure, SRS staff members stated that similar high concentrations of aluminum and silicon were used in their efforts to produce large aluminosilicate solids. However, the key step in the formation of the aluminosilicate plug is the agitation at $70^{\circ} \mathrm{C}$. The plugs in the evaporator at the SRS occurred primarily at the ends of the GDL. The tank waste at the ends of the GDL would be subjected to an increase in turbulence or agitation, and the temperature in this line would be significantly below the boiling point. Therefore, the agitation at $70^{\circ} \mathrm{C}$ would appear to be a reasonable approximation for the conditions in the GDL.

\subsection{MODELING FOR THE FORMATION OF ALUMINOSILICATES}

As the $\mathrm{pH}$ of caustic solutions increases, the solubilities of aluminum and silicon increase due to the formation of charged complexes such as the aluminate ion and a variety of silicate ions. However, the behavior of the individual components does not adequately represent the behavior of aluminum and silicon when they are combined. If even trace amounts of aluminum or silicon are present, precipitation of the other element can be induced. Furthermore, the precipitation of aluminosilicates cannot be prevented through increases in caustic concentration. Because a wide variety of aluminosilicates can form, this study considered three forms of aluminosilicates which are listed in Table 10. Several aqueous complexes of silicon were also considered, which included small polymers and ions (Hunt et al., 1999). A literature search of aluminum solubility provided additional information (Wesolowski, 1992).

Table 10. Aluminum, silicon, and aluminosilicate solids used in the SOLGASMIX model

\begin{tabular}{ccc}
\hline Name & Chemical formula & $\Delta \mathrm{G}^{\circ} / \mathrm{RT}$ \\
\hline Gibbsite & $\mathrm{Al}(\mathrm{OH})_{3}$ & -459.665 \\
Amorphous silica & $\mathrm{SiO}_{2}$ & -342.911 \\
Nepheline & $\mathrm{NaAlSiO}_{4}$ & -798.771 \\
Kaolinite & $\mathrm{Al}_{2} \mathrm{O}_{3} \cdot 2 \mathrm{SiO}_{2} \cdot \mathrm{H}_{2} \mathrm{O}$ & -1532.765 \\
Cancrinite & $3 \mathrm{Na}_{2} \mathrm{O} \cdot 3 \mathrm{Al}_{2} \mathrm{O}_{3} \cdot 6 \mathrm{SiO}_{2} \cdot 1.68 \mathrm{NaNO}_{3} \cdot 4.1 \mathrm{H}_{2} \mathrm{O}$ & -5454.573 \\
\hline
\end{tabular}

The supernatants at the SRS can be described as average, high hydroxide, or high nitrate. A chemical simulant for each type of supernatant (Walker, 1999) was used in this project. The 
SOLGASMIX code, a chemical equilibrium model, was used to predict whether the SRS simulants would contain solids. The results of chemical equilibrium calculations are shown in Table 11. For each simulant, the formation of an aluminosilicate solid in the form of cancrinite was predicted. The equilibrium calculations also predicted that the high-nitrate simulant would contain other solids as well. Figure 3 shows the phase diagram for aluminosilicate behavior in SRS simulants. While the aluminum and silicon concentrations were varied, the total sodium concentration was fixed at $5.6 M$ for each simulant. It is important to note that the solubility is very low throughout the ranges for both components.

Table 11. Results of equilibrium calculations on the SRS simulants

\begin{tabular}{ccccc}
\hline Phase & Name & $\begin{array}{c}\text { Average simulant } \\
(\mathrm{mol} / \mathrm{kg})\end{array}$ & $\begin{array}{c}\text { High nitrate simulant } \\
(\mathrm{mol} / \mathrm{kg})\end{array}$ & $\begin{array}{c}\text { High hydroxide simulant } \\
(\mathrm{mol} / \mathrm{kg})\end{array}$ \\
\hline Aqueous & Aluminate & 0.288 & 0.186 & 0.289 \\
& Silicon & $2 \mathrm{E}-7$ & $4 \mathrm{E}-9$ & $6 \mathrm{E}-7$ \\
& Hydroxide & 2.231 & 1.545 & 3.322
\end{tabular}

Solid

Average simulant

Cancrinite
High nitrate simulant

Cancrinite

Gibbsbite

$\mathrm{Na}_{2} \mathrm{SO}_{4} \cdot \mathrm{NaF}$

As shown in Table 11, the sodium sulfate-sodium fluoride double salt was predicted to precipitate out of the high-nitrate simulant. The presence of this double salt was experimentally confirmed by researchers at the SRS, as well as observed during dissolution experiments on actual saltcake samples for Hanford tanks BY-102 and TX-113 (Hunt et al., 2000). The solubility of the double salt in the average and high-nitrate simulants was predicted through a series of SOLGASMIX calculations using various concentrations of fluoride and sulfate. Figure 4 shows a phase diagram of sodium sulfate-sodium fluoride double salt in the average and high-nitrate simulants. In Fig. 4, the solid curves indicate a constant sodium concentration of $5.6 \mathrm{M}$; the fluoride and sulfate concentrations were varied from the original values in the SRS simulants. The dashed curve 


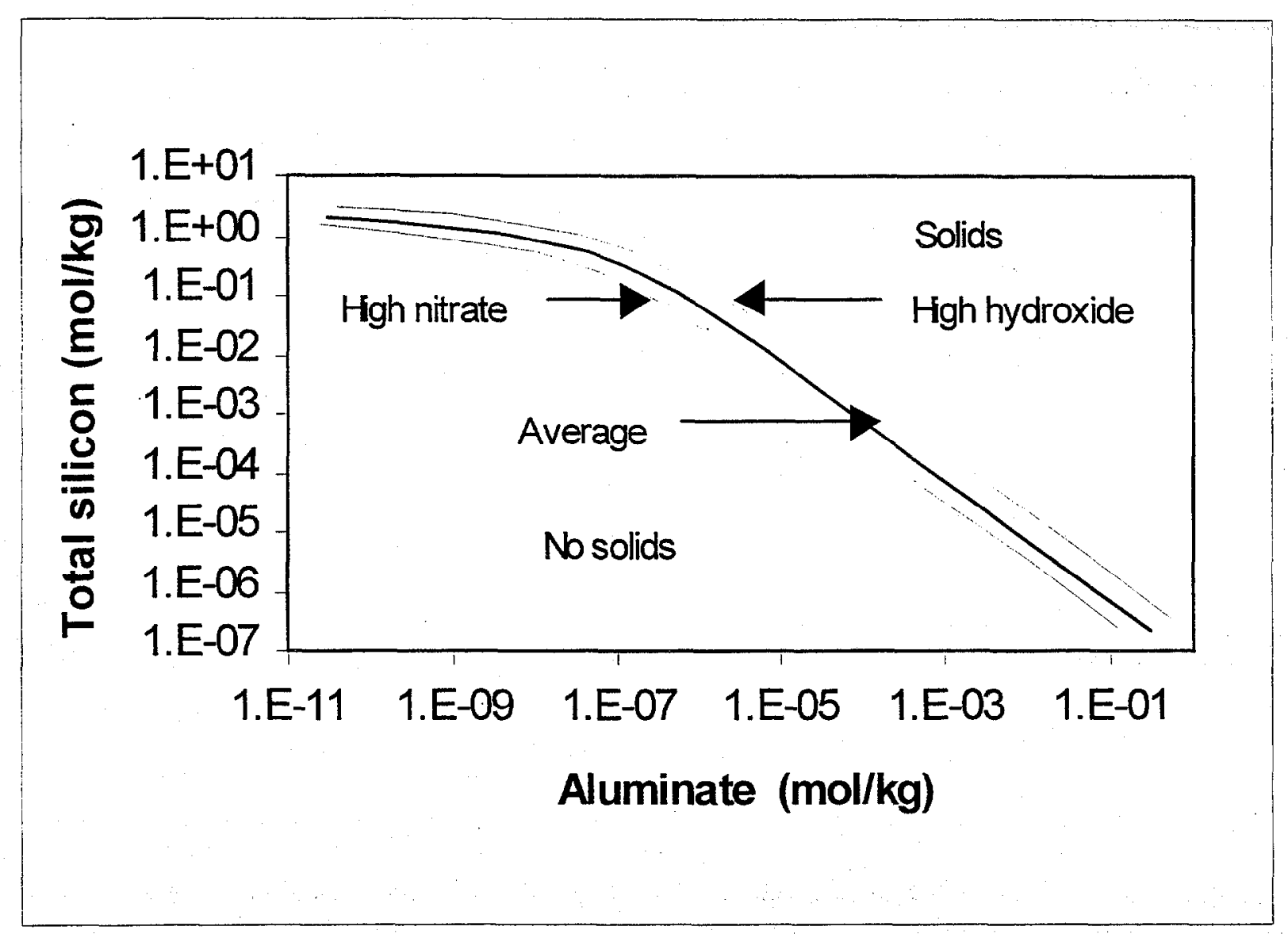

Fig. 3. Aluminum and silicon phase diagram for the Savannah River simulants. Curves represent high hydroxide (top), average (middle), and high nitrate (bottom) simulants.

indicates that precipitation of the double salt requires a sodium concentration in excess of $5.6 M$ to accommodate the increases in fluoride and sulfate concentrations. The diamond symbols indicate the fluoride and sulfate concentrations in the original formulations of the average and high-nitrate simulants (Walker, 1999). For the average simulant, the diamond symbol is below the solubility curve; therefore, precipitation of the double salt should occur. For the high-nitrate simulant, the diamond symbol is directly on the solubility curve, which indicates that the double-salt solid will form.

The model of sodium fluoride-sodium sulfate is based on solubility data at 18,25 , and $35^{\circ} \mathrm{C}$ (Linke, 1965). However, it is known from qualitative experiments that the double salt can form at 


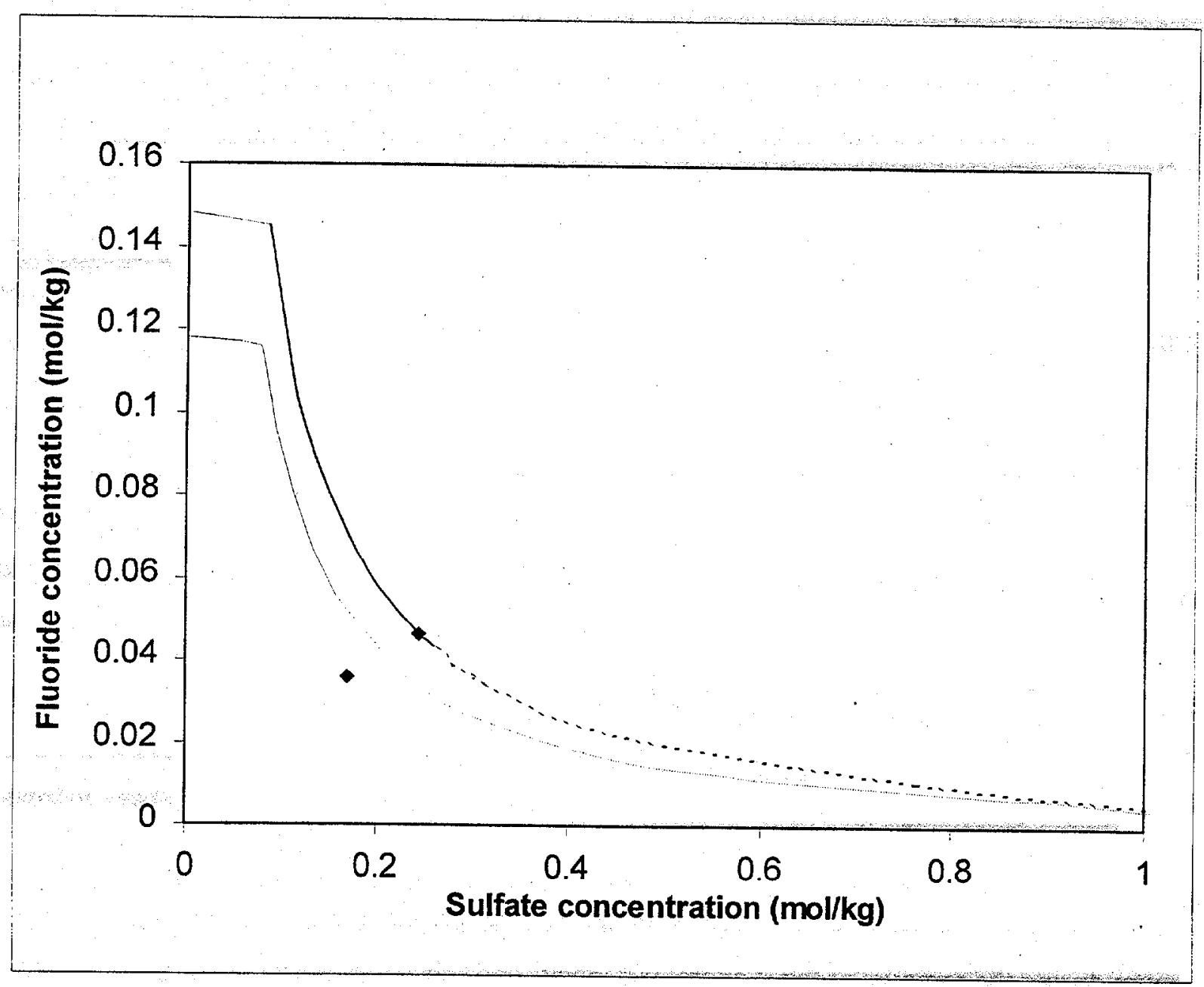

Fig. 4. Sodium, fluoride, and sulfate solubility diagram for the Savannah River simulants. Curves represent high nitrate (top) and average (bottom) simulants.

higher temperatures. At MSU, solubility tests on this system at $50^{\circ} \mathrm{C}$ and higher are under way; these results will be added to the model in FY 2001.

Identification of the potential precipitation products in the SRS simulants is important because these simulants are at the point of saturation for several chemical compounds. If a remediation process slightly increases or decreases the temperature of the waste, it will impact the solubility of the chemical constituents in the waste. Therefore, precipitation can occur. The combination of different waste streams can also result in precipitation. The aluminosilicate problem in the evaporator system is due to both of these factors. Tank waste with a high aluminum 
concentration was combined with a high-silicon waste stream from the vitrifier. In the evaporator system, the combined waste was then subjected to a wide range in temperature. While sodalite and sodium diuranate formed in the evaporator system, other solids such as gibbsite may also be found in the average and high-nitrate simulants (Walker, 1999). For the average simulant, the diamond symbol is below the solubility curve; therefore, the precipitation of the double salt should not occur. For the high-nitrate simulant, the diamond symbol is directly on the solubility curve (i.e., the level at which the double-salt solid will form). When precipitation does occur, it is critical to know the impact of the solids on the remediation processes. For example, the solids could lead to a plugged pipeline or ion-exchange column. After the thermodynamically possible precipitants have been identified, it is also important to evaluate the reaction kinetics. The precipitation reactions may be sufficiently slow that remediation processes are not significantly impacted. Therefore, a careful evaluation of potential precipitation products is vital to avoid costly delays in waste remediation.

\subsection{URANIUM PRECIPITATION WITH ALUMINOSILICATES}

Recently, the concerns about the deposits in the 242-16H evaporator system have increased dramatically. In addition to the aluminosilicates, solids with enriched uranium were also detected in the evaporator deposits. Due to the potential for nuclear criticality, the fate of the enriched uranium during the removal of the evaporator deposits and subsequent processing of uranium must be determined. Therefore, it is quite important to understand the chemical forms of the solids in the evaporator and the possible interactions between the solids and the proposed processes to remove the evaporator deposits. It will also be essential to evaluate the fate of the enriched uranium during subsequent waste processing.

The formulations of the average, high-hydroxide, and high-nitrate simulants for Savannah River do not include uranium. Soluble and insoluble uranium species were added to the SOLGASMIX model in order to predict the fate of the uranium in the average simulant. The uranyl ion was chosen as the soluble uranium species, even though various polymeric species can exist in relatively large quantities in caustic solutions (Baes et al., 1976). However, at very low aqueous concentrations, the consideration of the uranyl ion alone should be adequate. Because sodium diuranate was previously identified in the evaporator deposits (Wilmarth et al., 1997a) and in a simulant of the Savannah River waste, this solid species was included in the model (Hobbs, 1999). 
It should be noted that the results were not definite; therefore, other uranium solids may also be present. While sodium diuranate can be expected in solutions with sodium hydroxide and sodium nitrate, the question about the effects of aluminum and silicon on uranium precipitation remained. A Savannah River study (Hobbs, 1999) revealed no evidence of the coprecipitation of aluminum and uranium in waste simulants. With respect to silicon, it is known that small additions of silica to uranyl solutions will induce the precipitation of uranyl silicates. Therefore, a uranyl silicate in the form of weeksite was added to the SOLGASMIX model even though only equilibrium results for weeksite were obtained in acidic solutions.

The SOLGASMIX predictions for the average Savannah River simulant with and without uranium are presented in Table 12. Without uranium, the SOLGASMIX model predicted that cancrinite would be the only solid in the average simulant. After a small amount of uranyl nitrate was added to the formulation of the average simulant, the solubility of the uranyl ion in the highly alkaline simulant was predicted to be quite low, as expected. The model also predicted the formation of a uranium precipitate in addition to the cancrinite. If the uranyl silicates were not permitted by the model, then the uranium solid was sodium diuranate. If the uranyl silicates were permitted, then the uranium precipitate was weeksite, not sodium diuranate. Therefore, the SOLGASMIX predictions suggest that the uranyl silicates are thermodynamically more stable than the sodium diuranate in caustic solutions. This observation must be considered to be preliminary since the solubility of uranyl silicate in caustic solutions is not known. However, it does suggest that the deposits may contain uranyl silicates in addition to the sodium diuranate.

Table 12. Solids and solubilities in the average simulant with and without uranium

\begin{tabular}{ccc}
\hline Conditions & Solids & Concentration $(m)$ \\
\hline No uranium & Cancrinite & Aluminum $=0.288$ \\
& & Silicon $<1 \mathrm{E}-5$ \\
Uranium with no uranyl & Cancrinite & Aluminum $=0.288$ \\
silicates possible & Sodium diuranate & Silicon $<1 \mathrm{E}-5$ \\
& & Uranium $=0.003$ \\
& & Aluminum $=0.291$ \\
Uranium with uranyl silicates & Cancrinite & Silicon $<1 \mathrm{E}-5$ \\
possible & Weeksite & Uranium $<1 \mathrm{E}-5$ \\
& & \\
\end{tabular}


The possibility of uranyl silicate formation is important since it can dramatically change the overall solubility behavior of the uranium deposits. Acid dissolution will be more effective on sodium diuranate than on uranyl silicates. In addition, the acid dissolution process may lead to the conversion of the sodium diuranate to uranyl silicate. This conversion would directly impact the removal of the evaporator deposit and possibly downstream processes. The presence of uranyl silicates would also make the use of gadolinium or other neutron poisons more complicated since the poison would be more likely to become separated from the uranium solids. Therefore, the uranium solids that are present or may form must be further evaluated and their solubility behaviors considered during the removal process and subsequent waste remediation.

\subsection{MODELING ASSUMPTIONS AND PARAMETER DERIVATIONS}

The SOLGASMIX calculations in this study required certain thermochemical results, which included the Gibbs free energy of formation for each species and ion-interaction parameters (Pitzer, 1991) to describe deviations from the ideal. Many parameters from previous studies (Hunt et al., 1999) were used. The ion-interaction parameters for uranyl carbonate, uranyl chloride, uranyl perchlorate, and uranyl nitrate were used in the model. The interaction parameters for uranyl chloride, uranyl perchlorate, and uranyl nitrate were very similar. Therefore, the values for uranyl nitrate were used for other uranyl interactions with monovalent anions. The uranyl carbonate values were used for other uranyl interactions with bivalent anions such as sulfate. Other parameters, which are shown in Table 13, were obtained using nonlinear least-squares analysis on solubility results (Gayer et al., 1955) and the empirical solubility relationship (Hobbs et al., 1996). Finally, equilibrium constants for several uranyl silicates were measured (Nguyen et al., 1992). These values

were used to derive the Gibbs energies of formation, which are shown in Table 13. It should be noted the solubilities of the uranyl silicates were measured at $30^{\circ} \mathrm{C}$ and in the $\mathrm{pH}$ range from 3 to 4.5. While these conditions are not found in the SRS tanks and equipment, the results still permit the derivation of thermodynamic parameters for input into computational models. 
Table 13. Derived parameters for the SOLGASMIX model at $25^{\circ} \mathrm{C}$

\begin{tabular}{|c|c|c|}
\hline Parameter & Species & Value (unitless) \\
\hline$\mu^{\circ} / \mathrm{RT}$ & $\mathrm{Na}_{2} \mathrm{U}_{2} \mathrm{O}_{7}$ & -1113.060 \\
\hline$\Theta$ & $\mathrm{Na}-\mathrm{UO}_{2}$ & -1.50272 \\
\hline$\Psi$ & $\mathrm{Na}-\mathrm{UO}_{2}-\mathrm{OH}$ & -0.2556 \\
\hline$\Psi$ & $\mathrm{Na}-\mathrm{UO}_{2}-\mathrm{NO}_{3}$ & 0.3879 \\
\hline$\mu^{\circ} / \mathrm{RT}$ & $\begin{array}{c}2 \mathrm{UO}_{3} \cdot \mathrm{SiO}_{2} \cdot 2 \mathrm{H}_{2} \mathrm{O} \\
\text { (soddyite) }\end{array}$ & -1483.56 \\
\hline$\mu^{\circ} / \mathrm{RT}$ & $\begin{array}{l}\mathrm{NaOH} \cdot \mathrm{UO}_{3} \cdot \mathrm{SiO}_{2} \cdot 2 \mathrm{H}_{2} \mathrm{O} \\
\quad \text { (sodium boltwoodite) }\end{array}$ & -1395.592 \\
\hline$\mu^{\circ} / \mathrm{RT}$ & 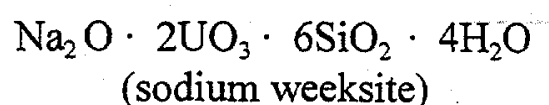 & -4817.955 \\
\hline
\end{tabular}

\section{ACKNOWLEDGMENTS}

This task was sponsored by the U.S. Department of Energy through the Office of Science and Technology's Tanks Focus Area. This work was performed at the Oak Ridge National Laboratory under the auspices of the Chemical Technology Division. Oak Ridge National Laboratory is managed by UT-Battelle, LLC, under contract DE-AC05-00OR22725.

\section{REFERENCES}

C. F. Baes and R. E. Mesmer. 1976. The Hydrolysis of Cations, John Wiley \& Sons, New York, pp. 174-180.

E. C. Beahm, C. F. Weber, D. D. Lee, T. A. Dillow, R. D. Hunt, C. M. Keswa, K. Osseo-Asare, and K. E. Spear. 1998. Status Report on Solid Control in Leachates, ORNL/TM-13660, Oak Ridge National Laboratory, Oak Ridge, Tennessee.

N. G. Colton, E. A. Daymo, W. L. Kuhn, and A. R. Felmy. 1998. Literature Review: Events, Phenomena, and Studies Pertinent to Technical Risks in the Waste Feed Delivery Project, Pacific Northwest National Laboratory, Richland, Washington. 
A. Francis, J. Henshaw, M. Manning, N. Pilkington, and C. Kemp. 2000. Progress Report on Precipitation Studies of Hanford Tank Simulant, AEAT/R/NS/0164, AEA Technology, Oxfordshire, United Kingdom.

K. H. Gayer and H. Leider. 1955. "The Solubility of Uranium Trioxide, $\mathrm{UO}_{3} \cdot \mathrm{H}_{2} \mathrm{O}$, in Solutions of Sodium Hydroxide and Perchloric Acid at $25^{\circ} \mathrm{C}, "$ J. Amer. Chem. Soc. 77, 1448.

D. L. Herting. 1980. "Evaporator Feeds High in Phosphate," Internal Letter \#65453-80-296, Rockwell Hanford Operations, Richland, Washington.

D. L. Herting. Personal communication to E. C. Beahm, Oak Ridge National Laboratory, Oak Ridge, Tennessee, September 14, 1998.

D. L. Herting. 1999. "U-Farm Cooling Test Results, Final Report," Numatec Hanford Corporation Internal Memo \#82800-99-039, Richland, Washington.

D. T. Hobbs. 1999. "Precipitation of Uranium and Plutonium from Alkaline Salt Solutions," Nucl. Tech. 128, 103.

D. T. Hobbs and D. G. Karraker. 1996. "Recent Results on the Solubility of Uranium and Plutonium in Savannah River Site Waste Supernate," Nucl. Tech. 114, 318.

R. D. Hunt, J. L. Collins, and C. W. Chase. 1998. Water Washes and Caustic Leaches of Sludge from Hanford Tank S-101 and Water Washes of Sludge from Hanford Tank C-103, ORNL/TM-13655, Oak Ridge National Laboratory, Oak Ridge, Tennessee.

R. D. Hunt, E. C. Beahm, C. W. Chase, J. L. Collins, T. A. Dillow, and C. F. Weber. 1999. Prevention of Solids Formation: Results of the FY 1999 Studies, ORNL/TM-1999/263, Oak Ridge National Laboratory, Oak Ridge, Tennessee.

R. D. Hunt, C. P. McGinnis, C. F. Weber, T. D. Welch, and J. R. Jewett. 2000. FY 2000 Saltcake Dissolution and Feed Stability Workshop, ORNL/TM-2000/202, Oak Ridge National Laboratory, Oak Ridge, Tennessee.

W. F. Linke. 1965. Solubilities, 4th Ed., American Chemical Society, Washington, D.C.

S. N. Nguyen, R. J. Silva, H. C. Weed, and J. E. Andrews, Jr. 1992. "Standard Gibbs Free Energies of Formation at the Temperature $303.15 \mathrm{~K}$ of Four Uranyl Silicates: Soddyite, Uranophane, Sodium Boltwoodite, and Sodium Weeksite," J. Chem. Thermodynamics 24, 359.

K. S. Pitzer. 1991. "Ion-Interaction Approach: Theory and Data Correlation," p. 105 in Activity Coefficients in Electrolyte Solutions, K. S. Pitzer, ed., 2nd Ed., CRC Press, Boca Raton, Florida. 
A. Shekarriz, Y. Onishi, P. A. Smith, M. Sterner, D. R. Rector, and J. Virden. 1997. Cross-Site Transfer System at Hanford: Long-Term Strategy for Waste Acceptance, PNNL-1 1497, Richland, Washington.

D. D. Walker. 1999. Preparation of Simulated Waste Solutions, WSRC-TR-00116, Westinghouse Savannah River Company, Aiken, South Carolina.

T. D. Welch, R. D. Hunt, J. S. Lindner, H. I. Alhabbash, R. K. Toghiani, R. Srivastava, and R. Lopez. 2000. Tank Waste Transport Stability FY 2000 Studies Slurry-Transport and Salt-Well-Pumping Testing and Modeling, ORNL/TM-2000/302, Oak Ridge National Laboratory, Oak Ridge, Tennessee.

D. J. Wesolowski. 1992. "Aluminum Speciation and Equilibria in Aqueous Solution: I. The Solubility of Gibbsite in the System Na-K-Cl-OH-Al- $(\mathrm{OH})_{4}$ from 0 to $100^{\circ} \mathrm{C}$, Geochim. Cosmochim. Acta. 56(3), 1065.

W. R. Wilmarth, S. D. Fink, D. T. Hobbs, and M. S. Hay. 1997a. Characterization and Dissolution Studies of Samples from the 242-16H Evaporator Gravity Drain Line, WSRC-TR-97-0326, Westinghouse Savannah River Company, Aiken, South Carolina.

W. R. Wilmarth, D. D. Walker, and S. D. Fink. 1997b. Sodium Aluminosilicate Formation in Tank $43 H$ Simulants, WSRC-TR-97-0389, Westinghouse Savannah River Company, Aiken, South Carolina. 
ORNL/TM-2000/298

\section{INTERNAL DISTRIBUTION}

\author{
1. A. G. Croff \\ 2-5. R. D. Hunt \\ 6. R. T. Jubin \\ 7. C. P. McGinnis \\ 8. L. E. McNeese \\ 9. J. C. Schryver
}

\author{
10. J. S. Watson \\ 11. C. F. Weber \\ 12. T. D. Welch \\ 13. Central Research Library \\ 14. ORNL Laboratory Records-RC \\ 15-16. ORNL Laboratory Records-OSTI
}

\section{EXTERNAL DISTRIBUTION}

17. Hani Al Habbash, 205 Research Boulevard, Starkville, MS 39759-9734

18. Harry Babad, Babad Technical Services, 2540 Cordoba Court, Richland, WA 99352

19. Joe Cruz, Department of Energy, Office of River Protection, P.O. Box 550, MSIN H6-60, Richland, WA 99352

20. John Garfield, Numatec Hanford Company, P.O. Box 1300, MSIN R3-73, Richland, WA 99352

21. Ken Gasper, CH2M Hill Hanford Group, P.O. Box 1500, MSIN H6-19, Richland, WA 99352

22. Pete Gibbons, Numatec Hanford Company, P.O. Box 1300, MSIN K9-91, Richland, WA 99352

23. Tom Gutman, U.S. Department of Energy, Savannah River Operations Office, P.O. Box A, Aiken, SC 29802

24. Dan Herting, Fluor Daniel, P.O. Box 1970, MSIN T6-07, Richland, WA 99352

25. David Hobbs, Westinghouse Savannah River Company, Savannah River Technology Center, Building 773-A, Aiken, SC 29808

26. Jim Honeyman, CH2M Hill Hanford Group, P.O. Box 1500, MSIN H6-62, Richland, WA 99352

27. Albert Hu, CH2M Hill Hanford Group, P.O. Box 1300, MSIN R2-11, Richland, WA 99352

28. James Jewett, Numatec Hanford Company, P.O. Box 1300, MSIN R3-73, Richland, WA 99352

29. Randy Kirkbride, Numatec Hanford Company, P.O. Box 1300, MSIN R3-73, Richland, WA 99352

30. Jeff Lindner, DIAL, 205 Research Boulevard, Starkville, MS 39759-9734

31. Ruben Lopez, Florida International University, 10555 West Flagler Street, CEAS 2100, Miami, FL 33174

32. Graham MacLean, FFS, P.O. Box 1050, MSIN G3-10, Richland, WA 99352

33. Jerome Morin, Westinghouse Savannah River Company, Savannah River Technology Center, Building 703- $\mathrm{H}$, Aiken, SC 29808

34. Yasuo Onishi, Pacific Northwest National Laboratory, P.O. Box 999, MSIN K7-15, Richland, WA 99352

35. Wally Schultz, W2S Company, 12704 Sandia Ridge Place, NE, Albuquerque, NM 87111 
36. Rajiv Srivastava, Florida International University, 10555 West Flagler Street, CEAS 2100, Miami, FL 33174

37. Walt Tamosaitis, Westinghouse Savannah River Company, Savannah River Technology Center, Building 773-A, Aiken, SC 29808

38. Tanks Focus Area Headquarters Program Lead, c/o Kurt Gerdes, DOE Office of Science and Technology, 19901 Germantown Road, 1154 Cloverleaf Building, Germantown, MD 20874-1290

39. Tanks Focus Area Program Manager, c/o T.P. Pietrok, U.S. Department of Energy, Richland Operations Office, P.O. Box 550, MSIN K8-50, Richland, WA 99352

40-47. Tanks Focus Area Technical Team, c/o B. J. Williams, Pacific Northwest National Laboratory, P.O. Box 999, MSIN K9-69, Richland, WA 99352

48. Becky Toghiani, Mississippi State University, School of Chemical Engineering, P.O. Box 9595, MS State, MS 39762

49. Bill Van Pelt, Westinghouse Savannah River Company, Savannah River Technology Center, Building 773-A, Aiken, SC 29808

50. Joe Westsik, Pacific Northwest National Laboratory, P.O. Box 999, MSIN K9-91, Richland, WA 99352

51. Bill Wilmarth, Westinghouse Savannah River Company, Savannah River Technology Center, Building 773-A, Aiken, SC 29808 